\title{
Pneumolysin as a potential therapeutic target in severe pneumococcal disease
}

\author{
Ronald Anderson ${ }^{1}$ and Charles Feldman ${ }^{2}$ \\ ${ }^{1}$ Department of Immunology and Institute of Cellular and Molecular Medicine, Faculty of Health \\ Sciences, University of Pretoria, Pretoria, South Africa. \\ ${ }^{2}$ Division of Pulmonology, Department of Internal Medicine, Charlotte Maxeke Johannesburg \\ Academic Hospital and Faculty of Health Sciences, University of the Witwatersrand, Johannesburg, \\ South Africa
}

Running title: Pneumolysin-targeted therapies

\begin{tabular}{|c|c|}
\hline \multirow{6}{*}{ Correspondence: } & Ronald Anderson \\
\hline & Department of Immunology \\
\hline & University of Pretoria \\
\hline & PO Box 667 \\
\hline & Pretoria \\
\hline & South Africa 0001 \\
\hline Telephone: & $+27-12-319-2425$ \\
\hline Telefax: & $+27-12-323-0732$ \\
\hline Email: & ronald.anderson@up.ac.za \\
\hline
\end{tabular}

\section{Highlights}

- Pneumolysin (Ply) is being increasingly implicated in the pathogenesis of acute organ damage and dysfunction during severe pneumococcal disease, particularly acute lung and cardiac injury.

- These harmful activities of Ply have been attributed to the cytotoxic, pro-inflammatory and platelet-activating properties of the toxin.

- Although challenging, therapeutic targeting of Ply is an attainable adjunctive strategy in severe pneumococcal disease.

- Currently, macrolides in particular appear to be the most effective Ply-neutralising agents. 


\section{Abstract}

Acute pulmonary and cardiac injury remain significant causes of morbidity and mortality in those afflicted with severe pneumococcal disease, with the risk for early mortality often persisting several years beyond clinical recovery. Although remaining to be firmly established in the clinical setting, a considerable body of evidence, mostly derived from murine models of experimental infection, has implicated the pneumococcal, cholesterol-binding, pore-forming toxin, pneumolysin (Ply), in the pathogenesis of lung and myocardial dysfunction. Topics covered in this review include the burden of pneumococcal disease, risk factors, virulence determinants of the pneumococcus, complications of severe disease, antibiotic and adjuvant therapies, as well as the structure of Ply and the role of the toxin in disease pathogenesis. Given the increasing recognition of the clinical potential of Plyneutralisation strategies, the remaining sections of the review are focused on updates of the types, benefits and limitations of currently available therapies which may attenuate, directly and/or indirectly, the injurious actions of Ply. These include recently described experimental therapies such as various phytochemicals and lipids, and a second group of more conventional agents the members of which remain the subject of ongoing clinical evaluation. This latter group, which is covered more extensively, encompasses macrolides, statins, corticosteroids, and platelettargeted therapies, particularly aspirin.

Keywords: aspirin; corticosteroids; macrolides; pneumococcus; protease-activated receptor 1; statins; Streptococcus pneumoniae; vorapaxar 


\section{Introduction: The burden of pneumococcal infection}

There have been several studies published in the recent literature attesting to the high clinical and economic burden of community-acquired pneumonia (CAP) in both developing and developed countries, with associated considerable morbidity and mortality. ${ }^{1-4}$ Furthermore, review of the worldwide literature indicates that currently the microbial aetiology of CAP can be established in up to $60 \%$ of cases of CAP, with Streptococcus pneumoniae (the pneumococcus) being the most common bacterial cause overall, irrespective of whether the cases are mild enough to be treated in the community, or whether admission to hospital or even the intensive care unit (ICU) is required. ${ }^{5}$ While pneumococcal infections may be invasive (organism present in normally sterile sites) or non-invasive, it is clear that the burden of both invasive and non-invasive pneumococcal disease in adults is determined primarily by the presence of pneumonia. ${ }^{6}$ However, while much is known about the incidence rates for CAP and invasive pneumococcal disease (IPD) in adults in developed countries, ${ }^{6}$ there is much less information on the burden of pneumococcal disease in adults in the developing world. ${ }^{7}$

There are a number of challenges remaining with regard to pneumococcal infections, not least of which are the limitations of the current diagnostic tools, particularly those for detection of non-bacteraemic infections, such that the incidence of pneumococcal pneumonia is most likely to be significantly underestimated. ${ }^{8}$ One systematic review and meta-analysis concluded that for every case of bacteraemic pneumonia there were likely to be at least three additional non-bacteraemic infections. ${ }^{9}$ Another systematic review of the burden of PCV-preventable pneumococcal disease in the United Kingdom indicated that it continues to be high despite the impact of PVC13 and that estimates of IPD cases represent a fraction of the total pneumococcal disease burden. ${ }^{10}$

Other important issues include the need for defining host risk factors for pneumococcal infections in adults and their possible association with mortality, as well as the role of the various serotypes in severity of illness and outcome and, lastly, the impact of various aspects of antibiotic treatment on mortality. ${ }^{8}$ It is 
concerning that despite all advances in medicine, the case fatality rate for patients hospitalised with IPD has remained constant in the region of $\sim 12 \%$ since the 1950 s. $^{8}$

\section{Risk factors for pneumococcal infections}

Much has been written recently specifically about risk factors for pneumococcal infections. ${ }^{11-15}$ Older age, or aging, possibly associated with immunosenescence, places individuals at risk for developing pneumococcal infections. ${ }^{15} \mathrm{~A}$ range of lifestyle factors (smoking, alcohol, being underweight, regular contact with children and poor dental hygiene) and underlying comorbid conditions (chronic respiratory disorders, especially chronic obstructive pulmonary disease; asthma; cardiovascular and cerebrovascular conditions; Parkinson's disease; epilepsy; diabetes mellitus; dementia; HIV infection; chronic renal and liver disease) not only increase the risk of pneumococcal infections, but may also impact negatively on both short-term and long-term outcomes following pneumococcal pneumonia. ${ }^{11,13}$ Patients with asplenia or splenic dysfunction, such as occurs in patients with sickle cell anaemia, are at significantly increased risk of fulminant infections with various microorganisms, and particularly the pneumococcus. ${ }^{16-19} \mathrm{It}$ is important to recognise that some adults, particularly those $\geq 65$ years, may have multiple comorbid conditions and that the odds ratios for acquiring IPD in individuals with two or more comorbid conditions may be comparable with those of conditions classified as being very high risk for development of CAP and IPD. ${ }^{14}$

Complement deficiencies predispose patients to infections with encapsulated bacteria, such as the pneumococcus, and polymorphisms in the human mannanbinding lectin gene (MBL2) have also been linked to increased susceptibility to pneumococcal infections. ${ }^{16}$ Immunoglobulin deficiencies have also been noted to be frequent in patients with pneumococcal infections, being particularly associated with IPD. ${ }^{20}$ Most toll-like-receptors and interleukin (IL)-1 receptors signal through myeloid differentiation primary response 88 (MyD88) and IL-1 receptor-associated kinase 4 (IRAK-4) and infants and young children with deficiencies in both these proteins are highly susceptible to IPD. ${ }^{21,22}$ Furthermore, patients with deficiencies of two proteins involved in the nuclear factor $\mathrm{KB}$ (NF-KB) signalling pathway, namely NF-kB essential modulator (NEMO) and ІкВк, have also been documented to increase susceptibility 
to infections with the pneumococcus. ${ }^{21}$ Lastly, environmental factors, such as the occurrence of influenza and other viral infections places individuals at risk of secondary bacterial infections in the lungs, particularly pneumococcal infections. ${ }^{12}$

\section{Virulence determinants and the pathogenesis of pneumococcal infections}

A myriad of review articles has been published recently, describing in detail the multiple virulence factors of the pneumococcus, as well as the pathogenesis of pneumococcal disease, a detailed description of which is beyond the scope of this manuscript. ${ }^{15,23-27}$ The obligatory first step in the pathogenesis of pneumococcal infections is colonisation of the nasopharynx by the microorganism, with the factors that govern colonisation having been fairly well characterised, including the antiphagocytic polysaccharide capsule, the pore-forming cytolysin, pneumolysin (Ply), surface adhesins, several of which also subvert complement deposition, pilus proteins, biofilm formation, and various enzymes. ${ }^{24,25,27}$ It is also important to note that the presence of other microbes in the nasopharynx can also influence pneumococcal colonisation and invasion. ${ }^{24,25}$

Development of IPD necessitates the translocation of the microorganism from the nasopharynx to the disease sites, including the lungs, bloodstream and meninges alone or in combination. ${ }^{26}$ The exact mechanisms underlying the transition of the pneumococcus from colonisation to invasion are incompletely understood and the subject of much study. ${ }^{27}$ However, at these disease sites, a complex interaction occurs between various pneumococcal virulence determinants and the immune defences of the host, which it is said produces four major effects, namely adhesion, invasion, inflammation and shock. ${ }^{26}$ A complex inflammatory response is initiated that arises from the interaction of the microorganism and its virulence determinants with host pattern receptors and signalling molecules expressed on phagocytes and other cells of the innate and adaptive immune systems and their associated mediators. ${ }^{26}$ This inflammatory response to the pneumococcus, "one of the most potent in medicine, has revealed the double-edged sword of clearance of infection at a cost of damage to host cells." 25 
It is well recognised that the clinical manifestations of pneumococcal infections, including their propensity to be associated with invasive disease and with antibiotic resistance, depend, to a large extent, on the particular capsular serotype causing infection. ${ }^{28}$ Review of the literature suggests that serotypes $1,4,5,7 \mathrm{~F}, 8$, $12 \mathrm{~F}, 14,18 \mathrm{C}$ and $19 \mathrm{~A}$ are more likely to be associated with IPD, and while 1 and $19 \mathrm{~A}$ are the predominant causes of IPD, serotype 14 remains the most common cause of non-bacteraemic pneumonia in adults. ${ }^{28}$ Serotype 1 pneumococci are somewhat different from other pneumococcal serotypes, as has been reviewed elsewhere. ${ }^{29}$ While being a common cause of IPD, serotype 1 is infrequently found as a nasopharyngeal coloniser. It causes infection in young patients without comorbidity and is associated with a low mortality. Interestingly, some serotype 1 pneumococci express a Ply that is incorporated into the eukaryotic cell membrane but which is not pore forming or haemolytic. ${ }^{29}$ While it is thought this variant Ply may impact on the pathophysiology of these serotype 1 pneumococcus infections and on the immune response to such infections, this has not been fully explored.

\section{Severe pneumococcal infection}

There are three main determinants of the intensity of inflammatory processes and outcome of infections, such as pneumococcal infections; these are factors related to the infective microorganism, the host, and therapy. ${ }^{23,30}$ Foremost among the microorganism-related factors that determine the outcome of serious pneumococcal infections are the serotypes causing the infection. ${ }^{31} \mathrm{~A}$ recent systematic review of the literature documented that certain clinical presentations, such as the occurrence of empyema (serotypes 1,3,5,7F,8,19A), necrotising pneumonia (serotype 3), septic shock (serotypes 3,19A), and meningitis (serotypes 10A,15B,19F,23F), as well as poorer outcomes, were related to specific pneumococcal serotypes. ${ }^{31}$ One population-based cohort study documented that serotypes 3,10A, 11A, 15B, 16F, $17 \mathrm{~F}, 19 \mathrm{~F}, 31$, and $35 \mathrm{~F}$ had a much higher mortality rate than serotype $1 .^{32}$ Another retrospective cohort study documented that compared to the reference group consisting of serotypes 1, 5, 7F, 15B, 20, 33F, serotypes 3, 6B, 9N, 16F, 18C 19F, and $23 \mathrm{~A}$ were associated with an increased case-fatality rate. ${ }^{33} \mathrm{~A}$ systematic review and meta-analysis confirmed that among bacteraemic cases, serotypes 1,7F and 8 
had reduced risk of death, while serotypes $3,6 \mathrm{~A}, 6 \mathrm{~B}, 9 \mathrm{~N}$, and $19 \mathrm{~F}$ had increased risk. $^{34}$

\section{Septic shock}

A number of studies of septic shock due to pneumococcal pneumonia have documented serotype 3 to be the important infecting agent. ${ }^{35,36}$ In this study, host factors that were identified as independent risk factors for septic shock were current tobacco use and chronic corticosteroid treatment. Importantly, the occurrence of septic shock was associated with more frequent requirement for mechanical ventilation ( $37 \%$ versus $4 \% ; p<0.001$ ), a longer hospital stay ( 11 versus 8 days; $p<0.001)$, and higher early (10\% versus $1 \%$; $p<0.001)$ and overall $(25 \%$ versus $5 \%$;

$\mathrm{p}<0.001$ ) case fatality rates. ${ }^{35}$ A number of risk factors for pneumococcal infection, described above, are also risk factors for a poorer short- and long-term outcome when pneumococcal infection occurs.

\section{Respiratory failure/ARDS}

Similarly, respiratory failure is a not an infrequent complication of pneumococcal pneumonia, being associated with considerable morbidity and mortality. ${ }^{37}$ Serotypes 3, 19A and 19F were reported to be most commonly associated with respiratory failure, with various host factors, such as age $>50$ years (OR $1.63(95 \% \mathrm{Cl} 1.15$ 2.3)), chronic lung disease (OR 1.54 (95\% Cl 1.1-2.15)), and chronic heart disease $\left(1.49\right.$ (95\% Cl 1.01-2.22) contributing to risk. ${ }^{37}$ With regard to acute respiratory distress syndrome (ARDS) as a cause of respiratory failure, serotypes 3, 4, 9A and $9 \mathrm{~V}$ ) were found in a much earlier study to be those mainly implicated. ${ }^{38}$ Much has been learned from both in vitro studies and animal models about the involvement of microbial and host factors in the pathogenesis of acute lung injury (ALI) in experimental pneumococcal infection. Witzenrath and colleagues documented that Ply appears to play a major role in early onset ALI in severe, experimental pneumococcal infection by causing impairment of the pulmonary microvascular barrier function with associated pulmonary hypertension. ${ }^{39}$ An earlier study had also documented that exposure of isolated rat alveolar epithelial cells to Ply resulted in lethal injury to the cells, while intra-pulmonary instillation of the toxin resulted in 
damage to alveolar epithelium, increased alveolar permeability, and widespread lung injury. ${ }^{40} \mathrm{~A}$ subsequent experimental study by Witzenrath and colleagues indicated that platelet activating factor (PAF) was a major contributor to Ply-induced ALI. ${ }^{41}$

\section{Acute cardiovascular events}

It is now also recognised that acute cardiac events occur in patients with pneumococcal pneumonia, with one study having documented an occurrence of $19.4 \%$ in 170 cases admitted to hospital. ${ }^{42}$ These included acute myocardial infarction, new onset arrhythmia and new or worsening cardiac failure, and were associated with a higher mortality rate than that which occurred in the group of patients who did not experience these events $(p<0.008)$. Some of these patients who developed acute cardiac events were relatively young and had no prior history of cardiac disease or cardiovascular risk factors. ${ }^{42}$ As with ALI, animal models of experimental pneumococcal infection have revealed major involvement of Ply, as well as that of pneumococcal phosphorylcholine which binds to the plateletactivating receptor, and possibly pathogen-derived hydrogen peroxide, in the pathogenesis of these cardiovascular events. ${ }^{43-45}$

\section{Therapy of severe pneumococcal infections}

The third determinant impacting on the outcome of patients with pneumococcal infections is the type of therapy, which may include both the use of antimicrobial agents and adjunctive therapies. ${ }^{23}$

\section{Antibiotic therapy}

A detailed description of antibiotic therapy for CAP, including pneumococcal CAP, is beyond the scope of the current manuscript, but has been described in the various CAP guidelines. ${ }^{46-48}$ The consensus opinion within these guidelines is that for severe pneumonia the antibiotic treatment alternatives are either a beta-lactam (or a betalactam/beta-lactamase inhibitor) plus a macrolide combination or a fluoroquinolone alone. ${ }^{46-48}$ However, a number of studies have suggested that for severe CAP, including pneumococcal CAP and for IPD, the best outcome appears to be achieved 
with the use of combination antibiotic therapy consisting of a beta-lactam together with a macrolide agent. ${ }^{49-53}$ However, uncertainty remains as to the reason(s) for the benefits of macrolide combination therapy with some believing that it may relate to the anti-inflmammatory/immunomodulatory effects of these agents. ${ }^{54}$ It also appears that early initiation of antibiotics in severe pneumococcal pneumonia or those hospitalised with bacteraemic pneumococcal pneumonia is associated with a better outcome ${ }^{52,55}$ such that some guidelines recommend that the initial antibiotic dose should be administered in the emergency department. ${ }^{46}$

\section{Adjunctive therapy}

It remains clear, however, that mortality due to pneumococcal pneumonia remains considerable despite all recent advances in medicine. ${ }^{8,56,57}$ As indicated above, the case fatality rate for patients hospitalised with IPD has remained at $\sim 12 \%$ since the 1950 s. ${ }^{8}$ A study of severe pneumococcal pneumonia requiring ICU admission documented that mortality remained high despite adequate antimicrobial therapy with hospital mortality reaching $28.8 \%{ }^{56}$ The Global Burden of Disease Study documented that globally in 2013, the pneumococcus was responsible for the largest number of lower respiratory tract infection deaths in people of all ages. ${ }^{57}$ It is for these reasons that much recent interest and research has been directed at the use of adjunctive therapies for patients with CAP and a myriad of different agents has been considered. ${ }^{58,59}$

Interestingly, a recent review by Lucas et al. published in 2013 was focused on potential adjunctive therapies directed against Ply, specifically on two categories of agent which may antagonise intracellular mechanisms involved in Ply-mediated increased epithelial permeability, these being agonists of growth hormone-releasing hormone and synthetic peptide mimics of the lectin-like domain of tumour necrosis factor- $\alpha$ (TNF- $\alpha){ }^{60}$ The current review differs substantially from that of Lucas et al. ${ }^{60}$ in several respects, most importantly more recent and broader coverage of Plytargeted therapies, encompassing those in both the pre-clinical and clinical stages of evaluation. Consideration of these strategies is preceded by brief updates on the structure and biological activities of Ply, as well as the involvement of the toxin in evasion of host defences. 


\section{Pneumolysin (Ply)}

\section{Structure and biological activities}

Ply, the major protein virulence factor of the pneumococcus belongs to the family of microbial cholesterol-binding, pore-forming toxins. ${ }^{61}$ Ply is produced by almost all of the currently known 97 serotypes of the pneumococcus, ${ }^{62}$ although clinical isolates of several subtypes, specifically sequence types (ST) 306 and 53 belonging to serotypes 1 and 8 respectively, have been found to harbour mutations in the ply gene which abolish pore-forming activity. ${ }^{63,64}$ Because Ply lacks a typical signal secretion leader sequence, extracellular release of the toxin is dependent on either bacterial autolysis or antibiotic-mediated bacteriolysis. ${ }^{61}$ It has also been reported that biologically-active Ply is present in the cell wall of many serotypes of the pneumococcus. ${ }^{65}$

Structurally, Ply consists of 471 amino acids and has a molecular weight of 53 $\mathrm{kDa}{ }^{61}$ The molecule consists of 4 distinct domains. Collectively, domains 1, 2, 3 are of inseparable structural importance, conferring stability on the Ply molecule, while domain 4, which consists of amino acid residues 360-469 forming the C-terminal region, promotes binding to the cholesterol moieties of cell membranes. ${ }^{61}$ Pore formation follows binding of the toxin to these plasma membrane cholesterol moieties via a threonine-leucine pair in a hydrophobic attachment region. ${ }^{66}$ Oligomerisation of the bound toxin monomers results in their assembly into circular pre-pores, an event which precedes a series of conformational changes resulting in the formation of membrane-piercing $\beta$-barrel pores of up to " $350 \AA$ in diameter with each pore consisting of as many as 50 Ply monomers". ${ }^{61}$ Notwithstanding toxin concentration, vulnerability to cell lysis is dependent on the age, cholesterol content and physical properties of the cell membrane, specifically bending rigidity and surface and dipole electrostatic properties, the latter being of significance given the "marked electronegative potential of Ply" ${ }^{67,68}$ The efficacy of cellular mechanisms which repair Ply-mediated damage to eukaryotic cell membranes is an additional determinant of cell lysis. These appear to be initiated by localised elevations in cytosolic $\mathrm{Ca}^{2+}$ in proximity to the Ply-punctured cell membrane and involve recruitment of annexins, actin-binding and other $\mathrm{Ca}^{2+}$-dependent proteins which seal 
both pre-pores and "mature pores". ${ }^{69}$ These events are followed by microvesicle expulsion of toxin pores. ${ }^{70}$ In addition, the cytolytic activity of Ply has been reported to be prone to oxidative inactivation, which may increase resistance to the toxin of phagocytic cells in particular via production of reactive oxygen species (ROS). ${ }^{71}$

In addition to pore formation, domain 4 also promotes activation of both the classical and lectin pathways of complement activation. ${ }^{61,72}$ In the case of the former, immunoglobulins $(\mathrm{lg})$ of the $\mathrm{IgM}$ class and $\lg \mathrm{G}_{3}$ subclass bind non-specifically to Ply via their $F_{c}$ regions. ${ }^{72}$ In the case of the latter, ficolin, a 1,3- $\beta$ glucan-binding lectin with acute phase reactant properties, binds specifically to Ply, triggering binding of $\mathrm{C} 3 \mathrm{~b}$ and complement activation. ${ }^{72}$ Ply-mediated complement depletion acting in concert with the anti-phagocytic polysaccharide capsule represent effective mechanisms by which the pathogen evades phagocytosis.

\section{Role of pneumolysin in evasion of host defences}

Notwithstanding disabling of complement-mediated protective immune mechanisms, it is the pore-forming cytolytic/pro-inflammatory activities of Ply which are the primary contributors to pneumococcal colonisation of the airways, invasion and extrapulmonary dissemination. ${ }^{73}$ In addition, a very recent pre-clinical study has implicated the toxin, via its pro-inflammatory activities, in host-to-host transmission of the pneumococcus, due to inflammation-associated bacterial shedding in nasal secretions. ${ }^{74}$ The involvement of Ply in the various stages of pneumococcal infection has recently been reviewed elsewhere ${ }^{73}$ and is considered only briefly here.

Together with various pneumococcal epithelial adhesins, as well as the polysaccharide capsule which, in addition to anti-phagocytic properties, enables attachment of the pathogen to airway mucus,$^{75} \mathrm{Ply}$ contributes to early colonisation not only via interference with the beating and coordinated expulsive actions of the mucociliary escalator, but also by directly damaging respiratory epithelium. ${ }^{76,77}$ Thereafter, the pneumococcus may be transiently controlled by innate host defences then eradicated following effective activation of both antibody- and cell-mediated host defences. ${ }^{78,79}$ Alternatively, the pneumococcus may enter a quiescent phase, often concealed in biofilm..$^{80-82}$ In the guise of a harmless, albeit menacing, 
nasopharyngeal commensal, the pneumococcus can re-emerge to invade the lungs when the airway defences of the host are transiently compromised, most notably during influenza infection. ${ }^{83}$

On reaching the lower airways, the pneumococcus encounters resident alveolar macrophages. Although actively phagocytic, these cells in the healthy lung are polarised, albeit reversibly, toward the anti-inflammatory M2 phenotype with limited antimicrobial activity. ${ }^{84,85}$ Notwithstanding cytotoxic effects on macrophages exposed to high concentrations of Ply in the extracellular milieu, induction of necroptosis by lower, non-lytic concentrations of the toxin may also occur when host defences are overwhelmed, reflecting different degrees of resistance to the pathogen and challenge levels. ${ }^{86-88}$ Death of these cells may also result from ingestion of pneumococci with resultant release of Ply from microorganisms entrapped in phagolysosomes, causing toxin-mediated apoptosis .9,90 $^{89}$

Necroptosis and apoptosis are distinct programmed cell-death processes. In the case of Ply-activated necroptosis, this involves triggering of the receptorinteracting serine-threonine kinases 1 and 3 (RIP1/3), albeit by mechanisms which remain to be established, but which result in phosphorylation of mixed lineage kinase domain-like (MLKL), which, in turn promotes membrane disruption, ion dysregulation, ATP depletion, and induction of intracellular oxidative stress. ${ }^{86-88,91} \mathrm{In}$ the case of apoptosis, which may also contribute to killing of the pneumococcus, this is triggered by Ply-mediated permeabilisation of the lysosomal/phagolysosmal membrane and activation of apoptosis via a mitochondrial-dependent mechanism. ${ }^{90}$ In addition, Ply-mediated permeabilisation of the phagolysosomal membrane has also been reported to cause leakage of pneumococcal cell wall components into the cytosol which may trigger cell death via activation of intracellular pathogen recognition receptors. ${ }^{92}$ In this context, it is noteworthy that exposure of human neutrophils to Ply results in activation of Nod-like receptor protein 3 (NLRP3). ${ }^{93,94}$ Ply-mediated activation of pro-inflammatory NLRP3 is considered to be protective against pneumococcal infection and may explain the virulence of non-cytolytic strains of the pneumococcus via evasion of NLRP3-activated inflammatory responses. On the other hand, hyper-activation of NLRP3 is likely to have deleterious consequences for the host. 
Ply-mediated subversion of pulmonary cellular host defences creates an environment conducive to survival and proliferation of the pneumococcus, predisposing to pulmonary damage involving, but not limited to, Ply-mediated direct cellular cytotoxicity, as well as indirect pro-inflammatory activity, with both mechanisms causing disruption of epithelial and endothelial barriers. ${ }^{39,95}$ These activities also favour extrapulmonary dissemination of the pneumococcus. In addition, as mentioned above, murine models of experimental pneumococcal lung infection have also identified additional mechanisms by which Ply may contribute to the pathogenesis of acute lung injury. These include intra-pulmonary platelet activation, resulting in microvascular leakage and pulmonary hypertension. ${ }^{41}$

As alluded to earlier, IPD has also been reported to pose a "substantial risk for a concurrent acute cardiac event, such as myocardial infarction, serious arrhythmia, or new or worsening congestive heart failure" ${ }^{42}$ Recent insights derived from murine models of experimental infection have convincingly demonstrated the involvement of Ply, as well as the adhesin, phosphorylcholine, in the pathogenesis of myocardial injury. ${ }^{43,44,88} \mathrm{Ply}$, via direct, pore-forming mechanisms, was found to impair cardiac function as a result of the formation of "unique cardiac microlesions". ${ }^{4}$ In addition to Ply-mediated cardiotoxicity, invasion of the myocardium by a nonpneumolysin-producing strain of the pneumococcus has also been reported to cause myocardial damage, possibly mediated by pathogen-derived hydrogen peroxide and/or metalloproteases. ${ }^{88}$

Pre-clinical studies have demonstrated that Ply, via its pore-forming activity, also causes platelet activation, secondary to influx of extracellular calcium, resulting in both homotypic platelet and heterotypic platelet:neutrophil aggregation. ${ }^{96-98}$ If operative in the clinical setting of IPD, these potentially pro-thrombotic mechanisms may also contribute to the pathogenesis of acute cardiac dysfunction.

\section{Pneumolysin as a therapeutic target in CAP}

Although the widespread uptake of efficacious pneumococcal conjugate vaccines, most recently PCV13, in national childhood immunisation programmes has impacted 
on the frequency of IPD in non-immunised adults via secondary ("herd") protection in some,${ }^{99,100}$ but not all, ${ }^{101}$ developed and developing countries, the incidence of, and mortality from, severe CAP remains considerable, even in the setting of seemingly appropriate antimicrobial chemotherapy. ${ }^{102}$ This is due in large part to world population ageing, particularly in developed countries, as well as to high rates of HIV infection in many developing countries, with the elderly and those infected with HIV being particularly vulnerable to the pneumococcus. Given the pivotal role played by Ply in the pathogenesis of IPD-associated organ damage and dysfunction, therapeutic targeting of the toxin represents a potentially advantageous strategy to bolster the efficacy of antibiotics. In this context, agents that target Ply fall into one or more of the following categories with examples of each shown in parenthesis:

- inhibitors of cytolytic activity, targeting binding to target cells and/or toxin oligomerisation (monoclonal antibodies, phytochemicals, cholesterol mimics)

- inhibitors of production (macrolides, macrolide-like agents, tetracyclines)

- inhibitors of cholesterol synthesis (statins)

- anti-inflammatory agents (macrolides, statins, corticosteroids)

- anti-platelet therapies (non-steroidal anti-inflammatory drugs, antagonists of the purinergic [P2Y12] receptor and protease-activated receptor 1 [PAR1])).

\section{Inhibitors of the cytolytic activity of pneumolysin}

Agents which directly target Ply include the murine monoclonal antibodies, PLY-4 and PLY-7, directed against various epitopes on the toxin which block binding to eukaryotic cells, as well as cytolytic activity. ${ }^{103}$ Also included in this category are $\beta$ sitosterol, a plant-derived cholesterol mimic, as well as liposomes composed of sphingomyelin/cholesterol. ${ }^{104-106}$ Several other plant-derived agents, viz. verbascoside, a phenylethanoid glycoside, and the bioflavanoids, apigenin and amentoflavone, all of which have been reported to block the oligomerisation of Ply 
monomers on cell membranes. ${ }^{107-109}$ Although all of these strategies have demonstrated protective efficacy in murine models of experimental pneumococcal infection, they have not, to our knowledge, progressed beyond the pre-clinical phase of evaluation. Future clinical development will require demonstration of ease of administration, adequate intestinal absorption in the case of orally-administered agents, cost effectiveness, compatibility with antibiotics, and, most importantly, convincing therapeutic benefit. Demonstration of therapeutic efficacy will be difficult due to critical dependence on rapid, accurate, and unequivocal diagnosis of pneumococcal infection in patients enrolled to clinical trials. This will be particularly challenging given that less than $50 \%$ of the causative pathogens in patients hospitalised with CAP are successfully identified using current laboratory diagnostic procedures. ${ }^{110,111}$

Although less selective, the remaining, and more extensively reviewed agents, viz. macrolides, statins, corticosteroids, and inhibitors of platelet activation, all have the potential to ameliorate the damaging activities of Ply. All are clinically available, and are the subject of ongoing evaluation as adjuvant therapies in bacterial CAP. Currently, however, no consensus exists regarding the most effective of these adjuvant therapies, with macrolides and corticosteroids having been the most researched and currently the most favoured. It must, however, be mentioned that a paucity of Ply/pneumococcus-specific data currently exists in relation to the agents reviewed in the following sections. Accordingly, the emphasis is placed on general effects on outcome, mostly in all-cause-CAP, supplemented with laboratory data and animal studies supportive of the involvement of Ply.

\section{Macrolides}

Based on evidence derived from a series of observational studies conducted between 1999 and 2010, such as that reported by Martin-Loeches et al., ${ }^{112}$ most national guidelines recommend combination therapy with a beta-lactam and a macrolide antibiotic as a strategy to lower in-hospital or ICU mortality in patients with severe CAP. ${ }^{53}$ Indeed, as stated in a recent review "the use of macrolides as part of combination antibiotic therapy has shown beneficial mortality effects across the CAP disease spectrum, especially for those with severe illness." ${ }^{113}$ O'Brien et al. have 
also stated that the "potential magnitude of the mortality benefits of combination treatment with a macrolide in CAP estimated at $20-50 \%$ cannot be overlooked" and that "such treatment should be obligatory for those admitted to an intensive care setting". ${ }^{114}$ Based on the findings of their recent systematic review, Horita et al. concluded that the all-cause mortality benefit of beta-lactam/macrolide combination therapy when compared with the beta-lactam alone was evident only in those patients with severe CAP, with the caveat that this contention is largely dependent on the influence of predominantly observational studies. ${ }^{115}$

\section{Macrolides and the pneumococcus}

In the case of severe pneumococcal CAP, the benefit of macrolide combination therapy is supported by two fairly recent studies, one an ICU-based, prospective, matched case-control study, ${ }^{52}$ and the other an in-hospital based, retrospective study, ${ }^{116}$ published in 2014 and 2013 respectively. Both studies documented significantly improved survival rates of those patients who received macrolide-containing combination therapy, most commonly with a beta-lactam antibiotic. $^{52,116}$

With respect to mechanisms of therapeutic efficacy, macrolides and macrolide-like agents possess a range of beneficial activities, targeting both the pathogen and the host, which enable them to complement beta-lactams in the adjuvant therapy of severe CAP, particularly pneumococcal CAP. Unlike the selective Ply-targeted agents described above, however, these protective activities of macrolides encompass a range of CAP bacterial pathogens, even extending to Gram-negative organisms. ${ }^{117,118}$

Macrolides and macrolide-like agents such as clindamycin, via their inhibitory effects on bacterial protein synthesis, are potent inhibitors of the production of Ply in vitro, ${ }^{119-124}$ as well as in the lungs of mice experimentally infected with the pneumococcus. ${ }^{120,124}$ The inhibitory effects of macrolides on the production of Ply by the pneumococcus in vitro are evident at sub-minimum inhibitory concentrations 
(MICs) of these agents and extend not only to macrolide-susceptible strains of the pneumococcus, but also to macrolide-resistant strains of the pathogen. ${ }^{121,122}$ Although data are limited, one study based on a murine model of experimental pneumonia in which the mice were infected with a highly macrolide-resistant strain of the pneumococcus co-expressing the erm $\mathrm{B}$ (ribosomal methylase) and mef $\mathrm{E} / \mathrm{A}$ (efflux pump) resistance genes, reported that administration of either azithromycin or clarithromycin resulted in significantly improved survival in the setting of decreased intrapulmonary concentrations of Ply. ${ }^{124}$ In addition, several clinical studies have reported on the disconnect between azithromycin resistance and the apparent efficacy of azithromycin monotherapy in the setting of macrolide-resistant pneumococcal pneumonia ${ }^{125,126}$ as well as various community-acquired respiratory tract infections (acute otitis media, CAP, acute bacterial exacerbations of chronic bronchitis, acute bacterial sinusitis), ${ }^{127}$ this discrepancy being known as the in vivo-in vitro paradox".

Potential mechanisms by which macrolides seemingly subvert macrolide resistance include transient inhibition of bacterial growth, ${ }^{128,129}$ as well as the high levels of intracellular accumulation of these antibiotics, achieving concentrations in phagocytic and epithelial cells possibly in excess of the MICs for macrolide-resistant strains of the pneumococcus. ${ }^{118}$ In the case of the former mechanism, exposure of highly macrolide-resistant (MIC values $>256 \mu \mathrm{g} / \mathrm{ml}$ ), erm B-expressing strains of the pneumococcus to either erythromycin or clarithromycin has been reported to delay the onset of bacterial growth for up to 10 hours, with the duration of the lag phase of growth varying somewhat according to the particular strain of the pneumococcus. ${ }^{128,129}$ In the study reported by Cockeran et al., transient inhibition of bacterial growth was not attributable to impaired induction of the erm $\mathrm{B}$ gene which actually exhibited a 4-fold increase in the level of gene transcription within $15 \mathrm{~min}$ of exposure of an erm B-expressing macrolide-resistant strain of the pneumococcus (strain 2507, serotype 23F) to clarithromycin. ${ }^{129}$ In this context, it is noteworthy that clarithromycin inhibits bacterial protein synthesis by binding to the peptide exit tunnel of the large $50 \mathrm{~S}$ subunit of the bacterial ribosome, thereby blocking peptide chain elongation, ${ }^{130}$ while expression of the erm $\mathrm{B}$ gene is also predominantly regulated post-transcriptionally. ${ }^{131,132}$ Despite the early increase in erm $B$ gene transcription following exposure of the pneumococcus to clarithromycin, synthesis of ribosomal 
methylase is therefore transiently hindered by the antibiotic, resulting in a prolonged lag phase prior to acquisition of the full resistance phenotype. ${ }^{129}$ Although speculative this mechanism of delayed acquisition of the resistance phenotype may extend to other types of inducible genetic antibiotic resistance, while weakening of the pathogen following exposure to innate host defences may also contribute to retardation of onset of resistance.

Even this brief window of therapeutic opportunity presented by macrolidemediated transient inhibition of synthesis of Ply, as well as other protein virulence factors by resistant strains of the pneumococcus, may be beneficial, especially in the context of combination therapy, by preventing excessive release of pro-inflammatory Ply due to beta-lactam-mediated bacteriolysis. ${ }^{120}$ In this context, the findings of a recently reported, retrospective, observational study conducted during January 2000 - December 2013 to which adults ( $n=643$ ) hospitalised with culture-proven pneumococcal pneumonia caused by both macrolide-susceptible $(n=504)$ and macrolide-resistant $(n=139)$ strains of the pathogen were recruited, are noteworthy. ${ }^{133}$ Guideline-compliant therapy was administered to a total of 437 patients of whom 346 and 91 were infected with macrolide-susceptible and macrolide-resistant strains of the pneumococcus respectively, while the corresponding numbers of patients treated with non-compliant antibiotic regimens were 154 and $47 .{ }^{133}$ The authors reported that no differences were evident in respect of disease severity on presentation, frequency of admission to ICU, and mechanical ventilation between the groups of patients infected with macrolide-susceptible or macrolide-resistant strains of the pneumococcus irrespective of guideline-compliant or -non-compliant antimicrobial therapy, while rates of non-invasive ventilation and shock were lower in the resistance group. However, no comparisons were reported in respect of the sub-groups of patients infected with macrolide-susceptible $(n=229)$ and macrolide-resistant $(n=69)$ strains of the pneumococcus treated with betalactam/macrolide combination therapy. ${ }^{133}$ Nonetheless, of those patients infected with a macrolide-resistant strain of the pneumococcus who received any type of combination therapy $(n=104)$, those treated with a macrolide-containing regimen ( $n=71$ of which 69 received a beta-lactam/macrolide regimen) had significantly lower rates of multilobar infiltration $(p<0.038)$ and ICU admission $(p<0.024){ }^{133}$ The authors, supported by an accompanying editorial, suggest that the observed benefits 
of macrolides in their study may result from the secondary, host-directed, antiinflammatory activities of these agents described below. ${ }^{133,134}$

This contention is supported by observations that administration of a betalactam/macrolide combination, which shows no synergistic activity against the pneumococcus in vitro, ${ }^{135}$ demonstrates significant survival benefits relative to those of the individual agents in a murine model of lethal pneumococcal (macrolidesusceptible) pneumonia. ${ }^{136}$ When compared with the individual agents, the beneficial effects of the ceftriaxone/azithromycin regimen used in this study were not associated with differences in lung bacterial loads at day 3 post-initiation of infection, but rather with immune modulation and anti-inflammatory activity characterised by decreased neutrophil influx. ${ }^{136}$

The aforementioned studies also highlight the difficulty in distinguishing the anti-inflammatory activity of macrolides resulting from inhibition of synthesis of Ply and other pro-inflammatory pneumococcal virulence factors due to primary antimicrobial activity, from the secondary, host-targeted mechanisms described below. Until the exact mechanisms underpinning the apparent benefit of betalactam/macrolide combination therapy of severe pneumococcal disease are unequivocally established, widespread acceptance of this strategy in the face of increasing levels of macrolide resistance is likely to remain contentious. Future options to improve efficacy include timing of administration of the macrolide, with the bacterial protein synthesis inhibitor given in advance of the beta-lactam as a potential strategy to curb the adverse, pro-inflammatory, bacteriolytic actions of the beta-lactam, thereby possibly increasing the efficacy of combination therapy. ${ }^{117}$ Additional options include combining beta-lactams with novel macrolides and macrolide-like agents, such as the fluoroketolide, solithromycin, which is highly active against both macrolide-susceptible and -resistant pneumococci. ${ }^{137-139}$

\section{Host-targeted anti-inflammatory activities of macrolides}

As mentioned above, macrolides possess secondary anti-inflammatory and immunomodulatory properties which are unrelated to their primary antimicrobial activity. Data documenting the cellular targets and mechanisms of these secondary 
activities has originated almost exclusively from pre-clinical in vitro studies and animal models of experimental therapy, which have been reviewed elsewhere. ${ }^{118,119}$ Briefly, macrolides effectively target neutrophils, interfering with cell migration via inhibition of the synthesis of the neutrophil-mobilising chemokine, interleukin (IL)-8, and the cytokines IL-17 and tumour necrosis factor (TNF)- $\alpha$, by cells of the innate and adaptive immune systems, as well as airway epithelial cells, fibroblasts and vascular endothelial cells. ${ }^{118,119}$ Macrolide-induced inhibition of the synthesis of these inflammatory mediators is achieved via antagonism of transcription factors which promote chemokine/cytokine gene activation such as nuclear factor kappa B (NFKB) and activator protein 1 (AP-1). ${ }^{118,119}$ In addition, exposure of airway epithelial cells to macrolides such as clarithromycin in vitro has been reported to inhibit dimerisation and subsequent nuclear translocation of the transcription factor, interferon regulatory factor 3 (IRF3), causing decreased synthesis of types I and III interferons (IFNs). ${ }^{140}$ Similarly, clarithromycin treatment of mice with elastase-induced emphysema experimentally infected with influenza virus protected the animals against subsequent challenge with the pneumococcus, which was associated with decreased concentrations of IFN- $\gamma$ in bronchoalveolar lavage fluid (BAL), as well as reductions in airway neutrophil and bacterial counts. ${ }^{141}$ In this context, it is noteworthy that excessive levels of type I interferons and IFN- $\gamma$, as may occur in the airways during influenza virus infection, have been reported to inhibit the phagocytic activities of alveolar macrophages, predisposing to secondary pneumococcal infection. ${ }^{142,143}$

One of the very few clinical studies addressing the effects of macrolide therapy of acute lung infection on systemic and pulmonary indices of inflammation has recently been reported by Lorenzo et al. ${ }^{144}$ These authors, using a prospective, longitudinal study design, compared the effects of varying types of antimicrobial therapy on the concentrations of IL-6, IL-8, IL-10, and TNF- $\alpha$ in the circulation and lungs of older CAP patients ( $n=52$ ) who had failed to respond satisfactorily, with those who had achieved clinical stability $(n=15)$ following 72 hours of antimicrobial therapy. ${ }^{144}$ Pathogen identification was made in $<50 \%$ of patients, with the pneumococcus identified as the causative pathogen in $21.7 \%$ and $27.6 \%$ of the former and latter groups respectively. Patients in the clinically unstable group were treated with fluoroquinolone (levofloxacin) monotherapy $(n=6)$, or combination 
therapy with either a beta-lactam (ceftriaxone/cefotaxime) or co-amoxicillin/clavulanic acid azithromycin $(n=23)$ or a beta-lactam + fluoroquinolone $(n=8)$, while the remainder $(n=15)$ received other types of therapy. ${ }^{144}$ For purposes of comparison, the patients were categorised according to the inclusion or exclusion of a macrolide in their therapeutic regimens ( $n=23$ vs 29 , and $n=9$ vs 6 for the clinically unstable and stable groups, respectively) and cytokine concentrations in blood and BAL were measured at 72 hours following initiation of therapy. In the clinically unstable group, treatment with macrolide-containing antibiotic regimens was associated with substantial reductions in the concentrations of all 4 of the measured cytokines in both blood and BAL in comparison with patients receiving non-macrolide regimens. ${ }^{144}$ These differences achieved statistical significance in the case of IL-8 and IL-10 in blood and IL- 6 and TNF- $\alpha$ in BAL. The anti-inflammatory activities of the macrolide-containing regimens were associated with statistically significant decreases in time to achieve clinical stability ( 8 vs 14 days, $p<0.007$ ) and length of hospital stay ( 12 vs 20 days, $p<0.007$ ). Differences in inflammatory and clinical indices between macrolide-containing and -non-containing regimens were not, however, evident in patients who had already achieved clinical stability in the setting of lower cytokine levels. ${ }^{144}$

Taken together with earlier studies, ${ }^{118,119}$ these more recent studies lend further support to the beneficial role of the anti-inflammatory/immunomodulatory activities of macrolides in the therapy of CAP, including, but not limited to, pneumococcal CAP.

\section{Statins}

Statins are widely used as cholesterol-lowering agents in the prevention and/or treatment of cardiovascular conditions and, theoretically, may be of benefit in their own right as adjunctive agents in the prevention of the cardiovascular complications of CAP. This therapeutic benefit is achieved via inhibition of the enzyme, 3-hydroxy3-methylglutaryl CoA reductase, resulting in inhibition of the synthesis of mevalonic acid, the precursor of cholesterol and other isoprenoids. In addition, targeting of synthesis of plasma membrane cholesterol with statins also represents a potential strategy to antagonise Ply and other bacterial, cholesterol-binding, pore-forming 
toxins, and indeed some evidence derived from experimental studies appears to support this contention. Two of these have reported that in vitro exposure of human airway epithelial cells or brain microvascular endothelial cells to simvastatin results in significant attenuation of the cytolytic actions of the toxin. The authors concede, however, that several mechanisms may underpin statin-mediated protection of eukaryotic cells against Ply, ${ }^{145,146}$ such as interference with G-protein receptormediated intracellular signalling via inhibition of synthesis of other isoprenoids. ${ }^{147}$ In addition to these in vitro studies, the protective potential of statins has also been demonstrated in a murine model of sickle cell disease in which significantly improved survival was observed in simvastatin-treated animals experimentally infected with the pneumococcus. ${ }^{146}$

To our knowledge, however, there are currently no reports of clinical trials addressing the issue of adjuvant therapy with statins in the setting of severe pneumococcal disease. There is, however, a number of observational studies, which have reported significantly improved survival of hospitalised patients with CAP who were already receiving statins for treatment of pre-existing cardiovascular conditions [reviewed in 102 and 147]. Notwithstanding the observational nature of these studies, "the healthy user effect" has also been identified as an additional caveat with respect to interpretation. ${ }^{147}$ Again, to our knowledge, there are only two reported prospective, controlled clinical trials which have investigated the possible benefit of adjuvant therapy with statins administered to patients with CAP at the time of hospitalisation. ${ }^{148,149} \mathrm{In}$ the first of these, patients were randomised to receive $20 \mathrm{mg}$ simvastatin $(n=19)$ or placebo $(n=15)$ within 24 hours of hospital admission and daily for 4 days thereafter. The primary clinical end-point was time to clinical stability, while secondary end-points included serum concentrations of IL-6, IL-10, TNF- $\alpha$, and C-reactive protein (CRP) measured 48 hours post-hospital admission. ${ }^{148}$ However, no differences were evident between the simvastatin-treated and the control groups of patients with respect to either clinical or inflammatory indices of disease activity. ${ }^{148}$

In a more recent and definitive, prospective clinical trial to which 2016 adult patients hospitalised with CAP were enrolled over a $2 \frac{1}{2}$ year period following admission to 5 different hospitals in Chicago $(n=3)$ and Nashville $(n=2)$ in the USA, the effects of statin use, most commonly simvastatin, prior to and during 
hospitalisation ( $n=483$ patients) on length of hospital stay (LOS) and in-hospital mortality were recorded. ${ }^{149}$ The authors reported that "in a large prospective study of adults hospitalized with CAP, we found no evidence to suggest that statin use before and during hospitalization improved LOS or in-hospital mortality". ${ }^{149} \mathrm{~A}$ limitation of this study, however, is the lack of inclusion of data on statin dose.

While this latter study in particular appears to discount a role for adjuvant therapy with statins in CAP, the issue of sub-groups of patients, such as those with pneumococcal CAP and those who smoke, ${ }^{150}$ the influence of dose and type of statin, as well as the possible interactions of statins with macrolides, require further investigation. With respect to the latter two points, the findings of the "SNOOPI" Trial (simvastatin to modify neutrophil function in older patients with septic pneumonia") are of interest. This is a UK-based, phase 4, randomised, placebo- controlled trial to which 61 clinically-matched patients aged $\geq 55$ years hospitalised with CAPassociated sepsis were randomised on admission to receive simvastatin $(n=31)$ at a comparatively high daily dose of 80 milligrams $(\mathrm{mg})$ continuing for 7 days, or a matched placebo $(n=30)$, some of whom were also receiving macrolides. ${ }^{151}$ The primary end-point was altered neutrophil extracellular trap (NET) formation at 3-4 days, while secondary end-points included neutrophil migration in vitro, safety and tolerability, length of hospital stay, re-admissions over a 6 month period, and mortality. No differences between the 2 groups with respect to NETosis were observed. However, in the case of the various secondary end-points, adjuvant therapy with simvastatin was associated with significantly improved neutrophil migration ( $p=0.033$ ). In addition, statin-treated patients "were less likely to have been (re)admitted to hospital or died compared to those in the placebo group (OR: 0,44, $95 \% \mathrm{Cl}: 0.21-0.91 ; \mathrm{p}=0.02)$ ", while the statin was well tolerated when co-prescribed with macrolides. ${ }^{151}$

Another recent, retrospective study determined the frequency of concurrent statin and macrolide administration in hospitalised patients diagnosed with pneumonia ( $n=162$ patient episodes), as well as the impact of continuation/interruption of statin therapy during hospitalisation on disease severity (measured by CURB score, survival at hospital discharge, and frequency of ICU admission), and the safety and tolerability of concurrent therapy. ${ }^{152}$ Sixty two percent 
of the cohort continued to receive concurrent administration of statins and macrolides throughout pneumonia treatment. In comparison with the group receiving macrolides in which administration of statins was interrupted, concurrent macrolide/statin therapy was associated with significant improvement in survival at hospital discharge (79\% vs $64 \%, p=0.034)$ and a decreased rate of admission to ICU (28\% VS 46\%, $p=0.0219$ ), while CURB scores and safety/tolerability criteria were similar in both groups. ${ }^{152}$ The authors concluded that "continued statin use during treatment for pneumonia is safe and may improve survival compared to stopping statin use. Current guidance on concurrent use of statins and macrolides should be reviewed". 152

Despite several negative reports, additional stringently controlled trials focused on statin adjuvant therapy in CAP appear warranted, with particular focus on the type, dose and duration of statin therapy, identification of those sub-groups of patients who are likely to be most responsive, and the possible beneficial interactions of statins with macrolides.

\section{Corticosteroids}

Although their possible effects on the pro-inflammatory activities of Ply appear to be unexplored, the broad-spectrum anti-inflammatory properties of corticosteroids enable these agents to suppress the pro-inflammatory activities of a range of cells of the adaptive and innate immune systems, as well as structural cells. ${ }^{153}$ Neutrophils are a possible exception due to anti-apoptotic interactions of corticosteroids with these cells. ${ }^{153}$ Like macrolides, corticosteroids act at the level of gene transcription, primarily by a mechanism known as tethered trans-repression which involves intracellular formation and nuclear translocation of a homodimeric complex of corticosteroids with the glucocorticoid receptor- $\alpha$. This complex, in turn, interacts with the transcription factors NFKB and AP-1 bound to their cognate DNA binding sites, resulting in recruitment of the enzyme, histone deacetylase, with resultant repression of genes encoding various pro-inflammatory cytokines, chemokines, adhesion molecules and enzymes. ${ }^{154,155}$ 
Three small, uncontrolled clinical studies. ${ }^{156-158}$ as well as studies in murine models of secondary pneumococcal pneumonia, ${ }^{159,160}$ have recorded benefit of adjuvant corticosteroid therapy in the treatment of severe pneumococcal disease. In the case of the latter studies, the first of these by Damjanovic et al. used a murine model of influenza and pneumococcal superinfection to investigate the protective potential of azithromycin and dexamethasone individually and in combination administered post-infection on survival, bacterial loads and dissemination, and lung immunopathology. Animals were initially infected with a non-lethal dose of murineadapted H1N1 influenza virus followed 7 days later by a "small dose" of a clinical isolate of serotype 3 of the pneumococcus. ${ }^{159}$ All animals infected with influenza virus alone survived, while a $100 \%$ mortality rate was observed within 72 hours in coinfected animals. Treatment of co-infected animals with azithromycin alone resulted in significantly improved survival and bacterial clearance, in the setting of essentially unchanged pulmonary inflammatory indices and immunopathology, while these parameters were unaffected by dexamethasone which caused only moderate antiinflammatory activity. ${ }^{159}$ Treatment with the combination of azithromycin and dexamethasone, on the other hand, was associated with the best rates of bacterial clearance and survival, as well as improvements in pulmonary inflammation and immunopathology. ${ }^{159}$ In a second, somewhat similar, study, Ghoneim et al., also using a murine model of influenza-related, secondary pneumococcal pneumonia with the same viral and bacterial pathogens as those used in the aforementioned study, investigated the effects of dexamethasone as an adjunct to antimicrobial therapy with ampicillin. ${ }^{160}$ These authors observed that treatment with ampicillin alone cured mice with mild pneumonia. ${ }^{160}$ However, even in the setting of decreased pulmonary bacterial loads, bactericidal ampicillin was found to be ineffective against severe disease, which was associated with antibiotic-mediated increased immunopathology, possibly due to increased release of Ply and other pro-inflammatory bacterial products from disintegrating bacilli. ${ }^{160}$ These adverse effects of ampicillin on survival and lung immunopathology in mice with severe pneumococcal disease were attenuated by inclusion of adjunctive dexamethasone. ${ }^{136}$ The authors of both of these experimental studies concluded that corticosteroids merit further study as adjunctive agents in the therapy of influenza-related, secondary pneumococcal pneumonia. $^{159,160}$ 
To our knowledge, however, no large, stringently controlled clinical trials have addressed the issue of adjuvant corticosteroid therapy in the clinical setting of severe pneumococcal disease. This situation contrasts with the use of corticosteroids in the adjuvant therapy of severe CAP, which has been the subject of a recent systematic review and meta-analysis, ${ }^{161}$ as well as a subsequent retrospective record review reported by Tagami et al. ${ }^{162}$ The review by Siemieniuk et al. concluded "that for hospitalized adults with CAP, systemic corticosteroid therapy may reduce mortality by approximately $3 \%$, need for mechanical ventilation by approximately $5 \%$, and hospital stay by approximately 1 day". ${ }^{161}$ In their study, Tagami et al. reported that the mortality benefit of adjuvant corticosteroid therapy was limited to those CAP patients with septic shock who had received catecholamines. ${ }^{162}$ In a review of these and other studies, Feldman et al. concluded that "although clarity is still required as to which specific subgroups (of patients) with CAP would benefit most from adjunctive corticosteroids, those with severe CAP, those with the highest inflammatory biomarker indices, such as CRP levels of $>150$ $\mathrm{mg} / \mathrm{L}$, and those with shock requiring vasopressor support, appear to experience greatest benefit". 163

In this context, a recently reported re-analysis of data ${ }^{164}$ derived from a randomised, placebo-controlled, clinical trial on the adjunctive efficacy of prednisone in patients hospitalised with CAP originally reported by Blum et al., ${ }^{165}$ and included in the Siemieniuk et al. systematic review, ${ }^{161}$ is noteworthy. In the re-analysis, the authors focused on sub-groups of patients with proven pneumococcal pneumonia ( $n=106,53$ each in the prednisone- and placebo-treated sub-groups), as well as on antibiotic-specific effects. ${ }^{164}$ Although the findings of the original trial revealed significant overall benefit of prednisone in all-cause CAP, specifically shorter time to clinical stability, the re-analysis revealed that this favourable response to adjunctive prednisone therapy was less evident in the sub-group of patients with pneumococcal pneumonia, being associated with longer duration of intravenous antibiotic therapy $(p=0.01) .{ }^{164}$ With respect to antibiotic effects, the authors also reported a "trend towards re-hospitalisation in the prednisone-treated compared with the placebotreated patients who did not receive $\beta$-lactam/macrolide combination therapy, as well as a trend towards re-hospitalisation in patients who received $\beta$-lactam monotherapy. Sensitivity analysis also confirmed such a trend in patients who had not received a 
macrolide which became statistically significant after adjustment for baseline characteristics". ${ }^{164}$ The authors do concede, however, that these findings should be interpreted cautiously. In an earlier randomised, controlled trial on adjuvant prednisolone therapy in patients hospitalised with CAP reported by Snjiders et al., ${ }^{166}$ which was also included in the Siemieniuk et al. review, ${ }^{161}$ sub-group analysis also revealed that patients with proven pneumococcal CAP experienced lower clinical cure rates at day 30 post-admission $(p=0.01)$ and more late failures $(p=0.02)$.

The apparent unresponsiveness of pneumococcal CAP to corticosteroid adjuvant therapy reported in these latter clinical studies ${ }^{164,166}$ may be attributed to the probable insensitivity of neutrophils to these agents, suggesting that the antiinflammatory efficacy of corticosteroids in pneumococcal CAP may be improved when used in combination with macrolides. However, this contention remains to be established and may be clarified pending the outcome of several ongoing clinical trials. ${ }^{163}$

\section{Agents which inhibit platelet activation}

\section{Aspirin}

In addition to their potential benefit in the prevention of the cardiac complications associated with all-cause CAP, recent pre-clinical studies documenting Ply-mediated activation of homotypic platelet aggregation and heterotypic nueutrophil:platelet aggregation suggest that anti-platelet therapies may be of adjunctive benefit in pneumococcal CAP. ${ }^{97,98,167,168}$ Several recent clinical studies have indeed implicated platelet activation in the pathogenesis of sepsis-associated ALI/ARDS/multi-organ dysfunction syndrome, ${ }^{169,170}$ as well as CAP-related acute cardiac events. ${ }^{171,172} \mathrm{~A}$ number of observational studies have reported that pre-hospital admission usage of inhibitors of platelet activation, mostly, but not limited to, aspirin, is associated with improved outcome in these clinical settings. ${ }^{171-177} \mathrm{~A}$ recent meta-analysis focused on both pre-clinical models and clinical studies on the prevention of, or treatment of ARDS with aspirin concluded that current evidence, although suggestive, is insufficient to support the use of aspirin in ARDS. ${ }^{178}$ The authors propose, however, 
that prospective randomised clinical trials appear justified, subsequent to the prior acquisition of clinical trial data on mechanisms of therapeutic action, which could be used "to guide optimal timing and dose". ${ }^{178}$

On a less optimistic note, however, two recent clinical trials failed to detect beneficial effects of administration of aspirin, either prior to, or following hospital admission on development of ALI or ARDS respectively. ${ }^{179,180}$ In the first of these, a large multicentre, international observational study to which 3,855 high-risk patients were enrolled, 976 of whom were receiving aspirin therapy prior to hospital admission, no statistically significant associations between pre-admission aspirin therapy and development of ALI were detected. ${ }^{179}$ The second was a multicentre, double-blind, placebo-controlled, phase $2 \mathrm{~b}$ clinical trial to which 390 patients at risk for ARDS were randomised to receive either aspirin (a $325 \mathrm{mg}$ loading dose, followed by $81 \mathrm{mg} /$ daily) or placebo ( $\mathrm{n}=195$ in each group) within 24 hours of emergency department presentation continuing daily for 7 days or until discharge or death. ${ }^{180}$ The authors of this study failed to detect beneficial effects of administration of aspirin in reducing the risk of ARDS at 7 days, leading them to conclude that the findings "of this phase $2 \mathrm{~b}$ clinical trial do not support continuation to a larger phase 3 trial." 180

Several other studies, have reported that usage of non-steroidal antiinflammatory drugs (NSAIDs), including aspirin, prior to hospital usage may actually predispose to worse outcomes in patients with CAP, including pneumococcal CAP, possibly as a consequence of masking of symptoms, leading to delayed administration of antibiotic therapy. ${ }^{181-183}$ In one of these studies, ${ }^{183}$ the authors also implicated suppressive effects of aspirin on innate pulmonary, anti-pneumococcal defences described in an earlier study. ${ }^{184}$ However, others have reported the opposite, observing that aspirin and other NSAIDs enhance the opsonophagocytosis and intracellular killing of both the pneumococcus and Klebsiella pneumoniae by human phagocytes both in vitro and ex vivo. ${ }^{185,186}$ 
To our knowledge no stringently controlled studies have been reported which document the protective potential of aspirin or other types of NSAID in pneumococcal CAP. It is, however, noteworthy, that aspirin has recently been reported to significantly increase mortality in a murine model of Ply-mediated ALI, following intra-tracheal injection of the toxin. ${ }^{187}$ The authors of this study observed that Ply caused potent activation of the synthesis of pro-inflammatory cysteinyl leukotrienes by airway mast cells, causing vascular leakage and bronchoconstriction. ${ }^{187}$ The adverse effects of aspirin on survival in this model of Plymediated ALI resulted from inhibition of the synthesis of another arachidonic acidderived, bioactive lipid, 12(S)-hydroxyheptadecatrienoic acid, which decreases sensitivity to cysteinyl leukotrienes by down-regulating expression of the counterreceptor, CysLTR1, on airway endothelial and smooth muscle cells. ${ }^{187}$ The findings of this pre-clinical study, taken together, with the aforementioned studies, suggest that aspirin adjunctive therapy may even be contra-indicated in pneumococcal CAP.

\section{PAR1 antagonists}

Other categories of pharmacological inhibitors of platelet activation such as antagonists of the P2Y12 purinergic receptor, or PAR1 antagonists, have not yet been evaluated in the clinical setting of pneumococcal CAP. We believe, however, that of these various agents only PAR1 antagonists are likely to be of therapeutic value in this context. This contention is based on the seemingly key involvement of platelet PAR1 in Ply-mediated heterotypic neutrophil:platelet aggregation. ${ }^{98}$ Only one PAR1 antagonist, vorapaxar, is currently clinically available for "the reduction of thrombotic cardiovascular events in higher-risk patients with a history of myocardial infarction or peripheral artery disease". ${ }^{188}$ Although not yet evaluated in the clinical settings of either all-cause CAP or pneumococcal CAP, the anti-inflammatory efficacy of this agent has been demonstrated in a murine model of experimental pneumococcal pneumonia, attenuating both pulmonary influx of neutrophils and alveolar leak, ${ }^{189}$ possibly by targeting endothelial PAR1 (murine platelets do not express this receptor).

The various categories of Ply-neutralising agent and their modes of action are summarised in Table 1. 
Table 1: Summary of agents which neutralise the pore-forming/anti-inflammatory activities of pneumolysin (Ply) directly and/or indirectly

\begin{tabular}{|c|c|c|}
\hline Agent & Mechanism of action & Current status \\
\hline $\begin{array}{l}\text { Murine monoclonal } \\
\text { antibodies (PLY-4 and } \\
\text { PLY-7) }\end{array}$ & $\begin{array}{l}\text { Interfere with both the binding of } \\
\text { Ply to target cells and } \\
\text { cytolyticactivity }^{103}\end{array}$ & $\begin{array}{l}\text { Have not been evaluated in the } \\
\text { clinical setting }\end{array}$ \\
\hline $\begin{array}{l}\text { B-sitosterol and } \\
\text { cholesterol/sphingomyelin- } \\
\text { loaded liposomes }\end{array}$ & $\begin{array}{l}\text { Cholesterol mimics which } \\
\text { antagonise binding of the } \\
\text { toxin }^{104-106}\end{array}$ & $\begin{array}{l}\text { Have not been evaluated in the } \\
\text { clinical setting }\end{array}$ \\
\hline $\begin{array}{l}\text { Verbascoside, apigenin, } \\
\text { amentoflavone }\end{array}$ & $\begin{array}{l}\text { Interfere with the oligomerisation } \\
\text { of Ply on cell membranes }{ }^{107-109}\end{array}$ & $\begin{array}{l}\text { Have not been evaluated in the } \\
\text { clinical setting }\end{array}$ \\
\hline Macrolide antibiotics & $\begin{array}{l}\text { - Inhibit production of } \mathrm{Ply}^{119-124} \\
\text { - Attenuate neutrophil } \\
\text { migration }\end{array}$ & $\begin{array}{l}\text { Recommended in most national } \\
\text { guidelines for treatment of CAP }\end{array}$ \\
\hline Statins & $\begin{array}{l}\text { - May antagonise Ply by } \\
\text { decreasing membrane } \\
\text { cholesterol } \\
\text { concentrations }{ }^{145,146} \\
\text { - Possess anti-inflammatory } \\
\text { activities }^{147}\end{array}$ & $\begin{array}{l}\text { Definitive clinical trials focused } \\
\text { on pneumococcal CAP and all- } \\
\text { cause CAP necessary }\end{array}$ \\
\hline Corticosteroids & $\begin{array}{l}\text { Broad spectrum anti- } \\
\text { inflammatory activity }\end{array}$ & $\begin{array}{l}\text { Increasing, but not yet } \\
\text { conclusive evidence for efficacy } \\
\text { in all-cause CAP; }{ }^{161,163} \text { efficacy } \\
\text { in severe pneumococcal disease } \\
\text { unknown, but concerns } \\
\text { exist }^{164,166}\end{array}$ \\
\hline Aspirin & $\begin{array}{l}\text { Inhibitor of thromboxane } \mathrm{A}_{2^{-}} \\
\text {mediated platelet activation }\end{array}$ & $\begin{array}{l}\text { Efficacy in all-cause } \\
\text { CAP/pneumococcal } \\
\text { CAP/ALI/ARDS uncertain }\end{array}$ \\
\hline Vorapaxar & Antagonist of platelet PAR $1^{188}$ & $\begin{array}{l}\text { No clinical trial data in all-cause } \\
\text { CAP/pneumococcal CAP } \\
\text { available }\end{array}$ \\
\hline
\end{tabular}

\section{Conclusions}

Ply is increasingly recognised as being a major contributor not only to pneumococcal colonisation of the airways, subversion of host defences, transmission and invasion, but also to the pathogenesis of acute organ damage and dysfunction, particularly acute lung and cardiac injury. Accordingly, therapeutic targeting of Ply as an adjunct to antimicrobial therapy has attracted considerable interest. Notwithstanding 
monoclonal antibody- and liposome-based Ply neutralisation strategies, recent preclinical studies have identified a number of low molecular weight phytochemicals which target the membrane-binding and/or pore-forming activities of the toxin. However, the efficacy of all of these remains to be evaluated in the clinical setting. Other categories of pharmacological agents which are the subject of ongoing evaluation as adjunctive therapies in CAP include macrolides, corticosteroids, statins and aspirin. Of these, macrolides, which target both the synthesis and proinflammatory activities of Ply, both directly and indirectly, appear to be the most effective, current adjunctive therapies in the setting of pneumococcal CAP, while uncertainty persists with respect to statins, corticosteroids and aspirin. The antiinflammatory adjunctive potential of the PAR1 antagonist, vorapaxar, described in a pre-clinical study remains to be evaluated in the clinical setting of pneumococcal CAP.

\section{Declaration}

Conflict of interest: none.

\section{Funding}

Charles Feldman is supported by The National Research Foundation of South Africa. 


\section{References}

1. Isturiz RE, Luna CM, Ramirez J. Clinical and economic burden of pneumonia among adults in Latin America. Int J Infect Dis 2010; 14: e852-6.

2. File TM Jr., Marrie TJ. Burden of community-acquired pneumonia in North American adults. Postgrad Med 2010; 122: 130-41.

3. Song JH, Thamlikitkul V, Hsueh PR. Clinical and economic burden of community-acquired pneumonia amongst adults in the Asia-Pacific region. Int $J$ Antimicrob Agents 2011; 38: 108-17.

4. Welte T, Torres A, Nathwani D. Clinical and economic burden of communityacquired pneumonia among adults in Europe. Thorax 2012; 67: 71-9.

5. Sanz Herrero F, Blanguer Olivas J. Microbiology and risk factors for communityacquired pneumonia. Semin Respir Crit Care Med 2012; 33: 220-31.

6. Drijkoningen JJ, Rohde GGU. Pneumococcal infection in adults: burden of disease. Clin Microbiol Infect 2014; 20: 45-51.

7. Scott JA. The preventable burden of pneumococcal disease in the developing world. Vaccine 2007; 25: 2398-405.

8. Ludwig E, Bonanni P, Rohde G, Sayiner A, Torres A. The remaining challenges of pneumococcal disease in adults. Eur Respir Rev 2012; 21: 57-65.

9. Said MA, Johnson HL, Nonyane BA, Deloria-Knoll M, O’Brien KL, AGEDD Adult Pneumococcal Burden Study Team, et al. Estimating the burden of pneumococcal pneumonia among adults: a systematic review and meta-analysis of diagnostic techniques. PLoS One 2013; 8: e60273.

10. Chalmers JD, Campling J, Dicker A, Woodhead M, Madhava H. A systematic review of the burden of vaccine preventable pneumococcal disease in UK adults. BMC Pulm Med 2016; 16: 77.

11. Torres A, Peetermans WE, Viegi G, Blasi F. Risk factors for community-acquired pneumonia in adults in Europe: a literature review. Thorax 2013; 68: 1057-65.

12. McCullers JA. The co-pathogenesis of influenza viruses with bacteria in the lung. Nat Rev Microbiol 2014; 12: 252-62.

13. Torres A, Blasi F, Dartois N, Akova M. Which individuals are at increased risk of pneumococcal disease and why? Impact of COPD, asthma, smoking, diabetes, and/or chronic heart disease on community-acquired pneumonia and invasive pneumococcal disease. Thorax 2015; 70: 984-9. 
14. Curcio $D$, Cané $A$, Isturiz $R$. Redefining risk categories for pneumococcal disease in adults: critical analysis of the evidence. Int $J$ Infect Dis 2015; 37: 30-5.

15. Feldman C, Anderson R. Epidemiology, virulence factors and management of the pneumococcus. F1000Res 2016; 5: 2320.

16. Ram S, Lewis LA, Rice PA. Infections of people with complement deficiencies and patients who have undergone splenectomy. Clin Microbiol Rev 2010; 23 : 740-80.

17. Chidiac C. Pneumococcal infections and adult with risk factors. Med Mal Infect 2012; 42: 517-24.

18. Sinwar PD. Overwhelming post splenectomy infection syndrome - review study. Int J Surg 2014; 12: 1314-6.

19. Theilacker C, Ludewig K, Serr A, Schimpf J, Held J, Bögelein M, et al. Overwhelming postsplenectomy infection: a prospective multicenter cohort study. Clin Infect Dis 2016; 62: 871-8.

20. Martinot M, Oswald L, Parisi E, Etienne E, Argy N, Grawey I, et al. Immunoglobulin deficiency in patients with Streptococcus pneumoniae or Haemophilus influenzae invasive infections. Int J Infect Dis 2014; 79: 79-84.

21. Picard C, Casanova JL, Puel A. Infectious diseases in patients with IRAK-4, MyD88, NEMO, or IKBa deficiency. Clin Microbiol Rev 2011; 24: 490-7.

22. Von Bernuth H, Picard C, Puel A, Casanova JL. Experimental and natural infections in MyD88- and IRAK-4-deficient mice and humans. Eur J Immunol 2012; 42: 3126-35.

23. Calbo E, Garau J. Factors affecting the development of systemic inflammatory response syndrome in pneumococcal infections. Curr Opin Infect Dis 2011; 24: 241-7.

24. Vernatter J, Pirofski LA. Current concepts in host-microbe interaction leading to pneumococcal pneumonia. Curr Opin Infect Dis 2013; 26: 277-83.

25. Henriques-Normark B, Tuomanen El. The pneumococcus: epidemiology, microbiology, and pathogenesis. Cold Spring Harb Perspect Med 2013; 3: 010215.

26. Donkor ES, Badoe EV. Insights into pneumococcal pathogenesis and antibiotic resistance. Adv Microbiol 2014; 4: 627-43. doi: 10.4236/aim.2014.410069

27. Wootton DG, Aston SJ, Gordon SB. The pathophysiology of pneumococcal pneumonia. In: Community-acquired pneumonia eds. JD Chalmers, MW Pletz, S 
Aliberti. European Respiratory Society. Eur Respir Monogr 2014; 63: 42-63. doi: 10.1183/1025448x.erm6314.

28. Song JY, Nahm MH, Moseley MA. Clinical implications of pneumococcal serotypes: invasive disease potential, clinical presentations, and antibiotic resistance. J Korean Med Sci 2013; 28; 4-15.

29. Ritchie ND, Mitchell TJ, Evans TJ. What is different about serotype 1 pneumococci? Future Microbiol 2012; 7: 33-46.

30. Luján M, Gallego M, Rello J. Optimal therapy for severe pneumococcal community-acquired pneumonia. Intensive Care Med 2006; 32: 971-80.

31. Grabenstein JD, Musey LK. Differences in serious clinical outcomes of infection caused by specific pneumococcal serotypes among adults. Vaccine 2014; 32 : 2399-405.

32. Harboe ZB, Thomsen RW, Riis A, Valentiner-Branth P, Christensen JJ, Lambertsen $\mathrm{L}$, et al. Pneumococcal serotypes and mortality following invasive pneumococcal disease: a population-based cohort study. PLoS Med 2009; 6: e1000081.

33. Jansen AG, Rodenburg GD, van der Ende A, van Alphen L, Veenhoven RH, Spanjaard L, et al. Invasive pneumococcal disease among adults: associations among serotypes, disease characteristics, and outcome. Clin Infect Dis 2009; 49: e23-9.

34. Weinberger DM, Harboe ZB, Sanders EA, Ndiritu M, Klugman KP, Rückinger S, et al. Association of serotype with risk of death due to pneumococcal pneumonia: a meta-analysis. Clin Infect Dis 2010; 51: 692-9.

35. Garcia-Vidal C, Ardanuy C, Tubau F, Viasus D, Dorca J, Liñares J, et al. Pneumococcal pneumonia presenting with septic shock: host- and pathogenrelated factors and outcomes. Thorax 2010; 65: 77-81.

36. Ahl J, Littorin N, Forsgren A, Odenholt I, Resman F, Riesback K. High incidence of septic shock caused by Streptococcus pneumoniae serotype 3 - a retrospective epidemiological study. BMC Infect Dis 2013; 13: 492.

37. Burgos J, Luján M, Larrosa MN, Fontanals D, Burmudo G, Planes AM, et al. Risk factors for respiratory failure in pneumococcal pneumonia: the importance of pneumococcal serotypes. Eur Respir J 2014; 43: 545-53. 
38. Fruchtman SM, Gombert ME, Lyons HA. Adult respiratory distress syndrome as a cause of death in pneumococcal pneumonia. Report of ten cases. Chest 1983; 83: 598-601.

39. Witzenrath M, Gutbier B, Hocke AC, Schmerck B, Hippenstiel S, Berger K, et al. Role of pneumolysin for the development of acute lung injury in pneumococcal pneumonia. Crit Care Med 2006; 34: 1947-54.

40. Rubins JB, Duane PG, Clawson D, Charboneau D, Young J, Niewoehner DE. Toxicity of pneumolysin to pulmonary alveolar epithelial cells. Infect Immun 1993; 61: 1352-8.

41. Witzenrath M, Gutbier B, Owen JS, Schmeck B, Mitchell TJ, Mayer K, et al. Role of platelet-activating factor in pneumolysin-induced acute lung injury. Crit Care Med 2007; 35: 1756-62.

42. Musher DM, Rueda AM, Kaka AS, Mapara SM. The association between pneumococcal pneumonia and acute cardiac events. Clin Infect Dis 2007; 45: 158-65.

43. Brown AO, Mann B, Gao G, Hankins JS, Humann J, Giardina J, et al. Steptococcus pnemoniae translocates into the myocardium and forms unique microlesions that disrupt cardiac function. PLoS Pathog 2014; 10: e1004383.

44. Alhamdi Y, Neill DR, Abrams ST, Malak HA, Yahya R, Barrett-Jolley R, et al. Circulating pneumolysin is a potent inducer of cardiac injury during pneumococcal infection. PLoS Pathog 2015; 11: e1004836.

45. Brown AO, Millett ER, Quint JK, Orihuela CJ. Cardiotoxicity during invasive pneumococcal disease. Am J Respir Crit Care Med 2015; 191: 739-45.

46. Mandell LA, Wunderink RG, Anzueto A, Barlett JG, Campbell GD, Dean NC, D et al. Infectious Diseases Society of America/American Thoracic Society consensus guidelines on the management of community-acquired pneumonia in adults. Clin Infect Dis 2007; 44: S27-S72.

47. Woodhead M, Blasi F, Ewig S, Garau J, Huchon G, leven M, et al. Guidelines for the management of adult lower respiratory tract infections - full version. Clin Microbiol Infect 2011; 17: E1 - E59.

48. Lim WS, Smith DL, Wise MP, Welham SA; British Thoracic Society. British Thoracic Society community-acquired pneumonia guideline and the NICE pneumonia guideline: how they fit together. Thorax 2015; 70: 698-700. 
49. Baddour LM, Yu VL, Klugman KP, Feldman C, Ortqvist A, Rello J, et al. Combination antibiotic therapy lowers mortality among severely ill patients with pneumococcal bacteremia. Am J Respir Crit Care Med 2004; 170: 440-4.

50. Lodise TP, Kwa A, Cosler L, Gupta R, Smith RP. Comparison of $\beta$-lactam and macrolide combination therapy versus fluoroquinolone monotherapy in hospitalized Veterans Affairs patients with community-acquired pneumonia. Antimicrob Agents Chemother 2007; 51: 3977-82.

51. Sligl WI, Asadi L, Eurich DT, Tjosvold L, Marrie TJ, Majumdar SR. Macrolides and mortality in critically ill patients with community-acquired pneumonia: a systematic review and meta-analysis. Crit Care Med 2014; 42: 420-32.

52. Gattarello S, Borgatta B, Solé-Violán J, Vallés J, Vidaur L, Zaragoza R, et al. Decrease in mortality in severe community-acquired pneumococcal pneumonia: impact of improving antibiotic strategies (2000-2013). Chest 2014; 146: 22-31.

53. Gattarello $S$. What is new in antibiotic therapy in community-acquired pneumonia? An evidence-based approach focusing on combined therapy. Curr Infect Dis Rep 2015; 17: 501.

54. Feldman C, Anderson R. Therapy for pneumococcal bacteremia: monotherapy or combination therapy? Curr Opin Infect Dis 2009; 22: 137-42.

55. Berjohn CM, Fishman NO, Joffe MM, Edelstein PH, Metlay JP. Treatment and outcomes for patients with bacteremic pneumococcal pneumonia. Medicine 2008; 87: 160-6.

56. Mongardon N, Max A, Bouglé A, Pène F, Lemiale V, Charpentier J, et al. Epidemiology and outcome of severe pneumococcal pneumonia admitted to intensive care unit: a multicenter study. Crit Care 2012; 16: R155.

57. GBD 2013 Mortality and Causes of Death Collaborators. Global, regional, and national age-sex specific all-cause and cause-specific mortality for 240 causes of death, 1990-2013: a systematic analysis for the Global Burden of Disease Study 2013. Lancet 2015; 385: 117-71.

58. Wunderink RG, Mandell L. Adjunctive therapy in community-acquired pneumonia. Semin Respir Crit Care Med 2012; 33: 311-8.

59. Faverio P, Restrepo MI. Non-antibiotic therapies for CAP. In: Communityacquired pneumonia eds. JD Chalmers, MW Pletz, S Aliberti. European Respiratory Society. Eur Respir Monogr 2014; 63: 219-33. doi: 10.1183/1025448x.erm6314. 
60. Lucas R, Czikora I, Sridhar S, Zemskov E, Gorshkov B, Sidderamappa U, et al. Mini-review: novel therapeutic strategies to blunt actions of pneumolysin in the lungs. Toxins 2013; 5: 1244-60.

61. Mitchell TJ, Dalziel CE. The biology of pneumolysin. Subcell Biochem 2014; 80 : 145-60.

62. Geno KA, Gilbert GL, Song JY, Skovsted IC, Klugman KP, Jones C, et al. Pneumococcal capsules and their types: past, present, and future. Clin Microbiol Rev 2015; 28: 871-99.

63. Kirkham LS, Jefferies JM, Kerr AR, Jing Y, Clarke SC, Smith A, et al. Identification of invasive serotype 1 pneumococcal isolates that express nonhemolytic pneumolysin. J Clin Microbiol 2006; 44: 151-9.

64. Jefferies JM, Johnston CH, Kirkham LS, Cowan GJ, Ross KS, Smith A, et al. Presence of nonhemolytic pneumolysin in serotypes of Streptococcus pneumoniae associated with disease outbreaks. J Infect Dis 2007; 196: 936-44.

65. Price KE, Camilli A. Pneumolysin localizes to the cell wall of Streptococcus pneumonia. J Bacteriol 2009; 191: 2163-8.

66. Farrand AJ, LaChapelle S. Hotze EM, Johnson AE, Tweten RK. Only two amino acids are essential for cytolytic toxin recognition of cholesterol at the membrane surface. Proc Natl Acad Sci U S A 2010; 107: 4341-6.

67. Bokori-Brown M, Petrov PG, Khafaji MA, Mughal MK, Naylor CE, Shore AC, et al. Red blood cell susceptibility to pneumolysin: correlation with membrane biochemical and physical properties. J Biol Chem 2016; 291: 10210-27.

68. Gilbert RJ, Sonnen AF. Measuring kinetic drivers of pneumolysin pore structure. Eur Biophys J 2016; 45: 365-76.

69. Wolfmeier H, Schoenauer R, Atanassoff AP, Neill DR, Kadioglu A, Draeger A, et al. $\mathrm{Ca}^{2+}$-dependent repair of pneumolysin pores: a new paradigm for host cellular defense against bacterial pore-forming toxins. Biochim Biophys Acta 2015; 1853 : 2045-54.

70. Wolfmeier H, Radecke J, Schoenauer R, Koeffel R, Babiychuk VS, Drücker P, et al. Active release of pneumolysin prepores and pores by mammalian cells undergoing a Streptococcus pneumoniae attack. Biochim Biophys Acta 2016; 1860: 2498-509.

71. Clark RA. Oxidative inactivation of pneumolysin by the myeloperoxidase system and stimulated human neutrophils. J Immunol 1986; 136: 4617-22. 
72. Ali YM, Kenawy HI, Muhammad A, Sim RB, Andrew PW, Schwaeble WJ. Human L-ficolin, a recognition molecule of the lectin activation pathway of complement, activates complement by binding to pneumolysin, the major toxin of Streptococcus pneumoniae. PLoS One 2013; 8: e82583.

73. Feldman C, Anderson R. The role of Streptococcus pneumoniae in communityacquired pneumonia. Semin Respir Crit Care Med 2016; 37: 806-18. Doi: 10.1055/s-0036-1592074.

74. Zafar MA, Wang Y, Hamaguchi S, Weiser JN. Host-to-host transmission of Streptococcus pneumoniae is driven by its inflammatory toxin, pneumolysin. Cell Host Microbe 2017; 21: 73-83.

75. Nelson AL, Roche AM, Gould JM, Chim K, Ratner AJ, Weiser JN. Capsule enhances pneumococcal colonization by limiting mucus-mediated clearance. Infect Immun 2007; 75: 83-90.

76. Feldman C, Mitchell TJ, Andrew PW, Boulnois GJ, Read RC, Todd HC, et al. The effect of Streptococcus pneumoniae pneumolysin on human respiratory epithelium in vitro. Microb Pathog 1990; 9: 275-84.

77. Hotomi M, Yuasa J, Briles DE, Yamanaka N. Pneumolysin plays a key role at the initial step of establishing pneumococcal nasal colonization. Folia Microbiol 2016; 61: 375-83.

78. Hermand P, Vandercammen A, Mertens E, Di Paolo E, Verlant V, Denoël P, et al. Preclinical evaluation of a chemically detoxified pneumolysin as pneumococcal vaccine antigen. Hum Vaccin Immunother 2017; 13: 220-8.

79. Zhang Z, Clarke TB, Weiser JN. Cellular effectors mediating Th17-dependent clearance of pneumococcal colonization in mice. J Clin Invest 2009; 119: 1899909.

80. Bergmann S, Lang A, Rohde M, Agarwal V, Rennemeier C, Grashoff C, et al. Integrin-linked kinase is required for vitronectin-mediated internalization of Streptococcus pneumoniae by host cells. J Cell Sci 2009; 122: 256-67.

81. Thornton RB, Rigby PJ, Wiertsema SP, Filion P, Langlands J, Coates HL, et al. Multi-species bacterial biofilm and intracellular infection in otitis media. $B M C$ Pediatr 2011; 11: 94.

82. Marks LR, Parameswaran GI, Hakansson AP. Pneumococcal interactions with epithelial cells are crucial for optimal biofilm formation and colonization in vitro and in vivo. Infect Immun 2012; 80: 2744-60. 
83. McCullers JA. Insights into the interaction between influenza virus and pneumococcus. Clin Microbiol Rev 2006; 19: 571-82.

84. Jones CV, Williams TM, Walker KA, Dickinson H, Sakkal S, Rumballe BA, et al. M2 macrophage polarisation is associated with alveolar formation during postnatal lung development. Respir Res 2013; 14: 41.

85. Yang Y, Wu BQ, Wang YH, Shi YF, Luo JM, Ba JH, et al. Regulatory effects of miR-155 and miR-146a on repolarization and inflammatory cytokine secretion in human alveolar macrophages in vitro. Immunopharmacol Immunotoxicol 2016. doi: 10.1080/08923973.2016.1248845. [Epub ahead of print].

86. González-Juarbe N, Gilley RP, Hinojosa CA, Bradley KM, Kamei A, Gao G, et al. Pore-forming toxins induce macrophage necroptosis during acute bacterial pneumonia. PLoS Pathog 2015; 11: e1005337.

87. Kitur K, Parker D, Nieto P, Ahn DS, Cohen TS, Chung S, et al. Toxin-induced necroptosis is a major mechanism of Staphylococcus aureus_lung damage. PLoS Pathog 2015; 11 : e1004820.

88. Gilley RP, González-Juarbe N, Shenoy AT, Reyes LF, Dube PH, Restrepo MI, et al. Infiltrated macrophages die of pneumolysin-mediated necroptosis following pneumococcal myocardial invasion. Infect Immun 2016; 84: 1457-69.

89. Aberdein JD, Cole J, Bewley MA, Marriott HM, Dockrell DH. Alveolar macrophages in pulmonary host defence the unrecognized role of apoptosis as a mechanism of intracellular bacterial killing. Clin Exp Immunol 2013; 174: 193202.

90. Bewley MA, Naughton M, Preston J, Mitchell A, Holmes A, Marriott HM, et al. Pneumolysin activates macrophage lysosomal membrane permeabilization and executes apoptosis by distinct mechanisms without membrane pore formation. MBio 2014; 5: e01710-14.

91. Chen X, Li W, Ren J, Huang D, He WT, Song Y, et al. Translocation of mixed lineage kinase domain-like protein to plasma membrane leads to necrotic cell death. Cell Res 2014; 24: 105-21.

92. Lemon JK, Weiser JN. Degradation products of the extracellular pathogen Streptotoccus pneumoniae access the cytosol via its pore-forming toxin. MBio 2015; 6: e02110.

93. Karmakar M, Katsnelson M, Malak HA, Greene NG, Howell SJ, Hise AG, et al. Neutrophil IL-1 $\beta$ processing induced by pneumolysin is mediated by the 
NLRP3/ASC inflammasome and caspase-1 activation and is dependent on $\mathrm{K}^{+}$ efflux. J Immunol 2015; 194: 1763-75.

94. Hassane M, Demon D, Soulard D, Fontaine J, Keller LE, Patin EC, et al. Neutrophilic NLRP3 inflammasome-dependent IL-1 $\beta$ secretion regulates the үठT17 cell response in respiratory bacterial infections. Mucosal Immunol 2017; doi: 10.1038/mi.2016.113 [Epub ahead of print].

95. García-Suárez Mdel M, Flórez N, Astudillo A, Vázquez F, Villaverde R, Fabrizio $\mathrm{K}$, et al. The role of pneumolysin in mediating lung damage in a lethal pneumococcal pneumonia murine model. Respir Res 2007; 8: 3.

96. Ohkuni H, Nagamune H, Ozaki N, Tabata A, Todome Y, Watanabe Y, et al. Characterization of recombinant Streptococcus mitis-derived human platelet aggregation factor. APMIS 2012; 120: 56-71.

97. Nel JG, Durandt C, Mitchell TJ, Feldman C, Anderson R, Tintinger GR. Pneumolysin mediates platelet activation in vitro. Lung 2016; 194: 589-93.

98. Nel JG, Durandt C, Theron AJ, Tintinger GR, Pool R, Richards GA, et al. Pneumolysin mediates heterotypic aggregation of neutrophils and platelets in vitro. J Infect 2017; doi: 10.1016/j.inf.2017.02.010 [Epub ahead of print].

99. Bonten MJ, Huijts SM, Bolkenbaas M, Webber C, Patterson S, Gault S, et al. Polysaccharide conjugate vaccine against pneumococcal pneumonia in adults. $N$ Engl J Med 2015; 372: 1114-25.

100. Bruce MG, Singleton R, Bulkow L, Rudolph K, Zulz T, Gounder P, et al. Impact of the 13-valent pneumococcal conjugate vaccine (pcv13) on invasive pneumococcal disease and carriage in Alaska. Vaccine 2015; 33: 4813-9.

101. Nair H, Watts AT, Williams LJ, Omer SB, Simpson CR, Willocks LJ, et al. Pneumonia hospitalisations in Scotland following the introduction of pneumococcal conjugate vaccination in young children. BMC Infect Dis 2016; 16: 390.

102. Feldman C, Anderson R. Community-acquired pneumonia: still a major burden of disease. Curr Opin Crit Care 2016; 22: 477-84.

103. García-Suárez Mdel M, Cima-Cabal MD, Flórez N, García P, CernudaCernuda R, Astudillo A, et al. Protection against pneumococcal pneumonia in mice by monoclonal antibodies to pneumolysin. Infect Immun 2004; 72: 4534-40. 
104. Cockeran R, Anderson R, Feldman C. Pneumolysin as a vaccine and drug target in the prevention and treatment of invasive pneumococcal disease. Arch Immunol Ther Exp 2005; 53: 189-98.

105. Li H, Zhao X, Wang J, Dong Y, Meng S, Li R, et al. $\beta$-Sitosterol interacts with pneumolysin to prevent Streptococcus pneumoniae infection. Sci Rep 2015; 5: 17668.

106. Henry BD, Neill DR, Becker KA, Gore S, Bricio-Moreno L, Ziobro R, et al. Engineered liposomes sequester bacterial exotoxins and protect from severe invasive infections in mice. Nat Biotechnol 2015; 33: 81-8.

107. Zhao X, Li H, Wang J, Guo Y, Liu B, Deng X, et al. Verbascoside alleviates pneumococcal pneumonia by reducing pneumolysin oligomers. Mol Pharmacol 2016; 89: 376-87.

108. Song M, Li L, Li M, Cha Y, Deng X, Wang J. Apigenin protects mice from pneumococcal pneumonia by inhibiting the cytolytic activity of pneumolysin. Fitoterapia 2016; 115: 31-6. Doi: 10.1016/j.fitote.2016.09.017.

109. Zhao X, Liu B, Liu S, Wang L, Wang J. Anticytotoxin effects of amentoflavone to pneumolysin. Biol Pharm Bull 2017; 40: 61-7.

110. Spoorenberg SM, Bos WJ, Heijligenberg R, Voorn PG, Grutters JC, Rijkers GT, et al. Microbial aetiology, outcomes, and costs of hospitalisation for community-acquired pneumonia; an observational analysis. BMC Infect Dis 2014; 14: 335 .

111. Jain S, Self WH, Wunderink RG, Fakhran S, Balk R, Bramley AM, et al. Community-acquired pneumonia requiring hospitalization among U.S. adults. $N$ Engl J Med 2015; 373: 415-27.

112. Martin-Loeches I, Lisboa T, Rodriguez A, Putensen C, Annane D, GarnachoMontero J, et al. Combination antibiotic therapy with macrolides improves survival in intubated patients with community-acquired pneumonia. Intensive Care Med 2010; 36: 612-20.

113. Bender MT, Niederman MS. Improving outcomes in community-acquired pneumonia. Curr Opin Pulm Med 2016; 22: 235-42.

114. Emmet O'Brien M, Restrepo MI, Martin-Loeches I. Update on the combination effect of macrolide antibiotics in community-acquired pneumonia. Respir Investig 2015; 53: 201-9. 
115. Horita N, Otsuka T, Haranaga S, Namkoong H, Miki M, Miyashita N, et al. Beta-lactam plus macrolides or beta-lactam alone for community-acquired pneumonia: a systematic review and meta-analysis. Respirology 2016; 21: 1193200.

116. Shorr AF, Zilberberg MD, Kan J, Hoffman J, Micek ST, Kollef MH. Azithromycin and survival in Streptococcus pneumoniae pneumonia: a retrospective study. BMJ Open 2013; 3: e002898.

117. Anderson R, Tintinger G, Cockeran R, Potjo M, Feldman C. Beneficial and harmful interactions of antibiotics with microbial pathogens and the host innate immune system. Pharmaceuticals 2010; 3: 1694-710. doi: 10.3390/ph3051694.

118. Steel HC, Theron AJ, Cockeran R, Anderson R, Feldman C. Pathogen- and host-directed anti-inflammatory activities of macrolide antibiotics. Mediators Inflamm 2012; 2012: 584262.

119. Lagrou K, Peetermans WE, Jorissen M, Verhaegen J, Van Damme J, Van Eldere J. Subinhibitory concentrations of erythromycin reduce pneumococcal adherence to respiratory epithelial cells in vitro. J Antimicrob Chemother 2000; 46: 717-23.

120. Spreer A, Kerstan H, Böttcher T, Gerber J, Siemer A, Zysk G, et al. Reduced release of pneumolysin by Streptococcus pneumoniae in vitro and in vivo after treatment with nonbacteriolytic antibiotics in comparison to ceftriaxone.

Antimicrob Agents Chemother 2003; 47: 2649-54.

121. Anderson R, Steel HC, Cockeran R, Smith AM, von Gottberg A, de Gouveia $\mathrm{L}$, et al. Clarithromycin alone and in combination with ceftriaxone inhibits the production of pneumolysin by both macrolide-susceptible and macrolide-resistant strains of Streptococcus pneumoniae. J Antimicrob Chemother 2007; 59: 224-9.

122. Anderson R, Steel HC, Cockeran R, von Gottberg A, de Gouveia L, Klugman $\mathrm{KP}$, et al. Comparison of the effects of macrolides, amoxicillin, ceftriaxone, doxycycline, tobramycin and fluoroquinolones, on the production of pneumolysin by Streptococcus pneumoniae in vitro. J Antimicrob Chemother 2007; 60: 11558.

123. Spreer A, von Ruden C, Mitchell TJ, Eiffert H, Nau R. Influence of subinhibitory concentrations of protein-synthesis-inhibiting antibiotics on production and release of the pneumococcal virulence factor pneumolysin in vitro. Chemotherapy 2007; 53: 327-31. 
124. Fukuda Y, Yanagihara K, Higashiyama Y, Miyazaki Y, Hirakata Y, Mukae H, et al. Effects of macrolides on pneumolysin of macrolide-resistant Streptococcus pneumoniae. Eur Respir J 2006; 27: 1020-5.

125. Yanagihara K, Izumikawa K, Higa F, Tateyama M, Tokimatsu I, Hiramatsu K, et al. Efficacy of azithromycin in the treatment of community-acquired pneumonia, including patients with macrolide-resistant Streptococcus pneumoniae infection. Intern Med 2009; 48: 527-35.

126. Kohno S, Tateda K, Kadota J, Fujita J, Niki Y, Watanabe A, et al. Contradiction between in vitro and clinical outcome: intravenous followed by oral azithromycin therapy demonstrated clinical efficacy in macrolide-resistant pneumococcal pneumonia. J Infect Chemother 2014; 20: 199-207.

127. Zhanel GG, Wolter KD, Calciu C, Hogan P, Low DE, Weiss K, et al. Clinical cure rates in subjects treated with azithromycin for community-acquired respiratory tract infections caused by azithromycin-susceptible or azithromycinresistant Streptococcus pneumoniae: analysis of Phase 3 clinical trial data. $J$ Antimicrob Chemother 2014; 69: 2835-40.

128. Wolter N, Smith AM, Farrell DJ, Northwood JB, Douthwaite S, Klugman KP. Telithromycin resistance in Streptococcus pneumoniae is conferred by a deletion in the leader sequence of erm(B) that increases rRNA methylation. Antimicrob Agents Chemother 2008; 52: 435-40.

129. Cockeran R, Steel HC, Wolter N, de Gouveia L, von Gottberg A, Klugman KP. Effects of clarithromycin at sub-minimum inhibitory concentrations on early ermB gene expression, metabolic activity and growth of an erm(B)-expressing macrolide-resistant strain of Streptococcus pneumoniae. Open J Respir Dis 2012; 2: 1-8. Doi: 10.4236/ojrd.2012.21001.

130. Zuckerman JM. Macrolides and ketolides: azithromycin, clarithromycin, telithromycin. Infect Dis Clin N Am 2004; 18: 621-49.

131. Weisblum B. Insights into erythromycin action from studies of its activity as inducer of resistance. Antimicrob Agents Chemother 1995; 39: 797-805.

132. Wozniak DJ, Keyser R. Effects of subinhibitory concentrations of macrolide antibiotics on Pseudomonas aeruginosa. Chest 2004; 125: 62S-9S.

133. Cilloniz C, Albert RK, Liapikou A, Gabarrus A, Rangel E, Bello S, et al. The effect of macrolide resistance on the presentation and outcome of patients 
hospitalized for Streptococcus pneumoniae pneumonia. Am J Respir Crit Care Med 2015; 191: 1265-72.

134. Niederman MS. Macrolide-resistant pneumococcus in community-acquired pneumonia. Is there still a role for macrolide therapy? Am J Respir Crit Care Med 2015; $191: 1216-7$.

135. Lin E, Stanek RJ, Mufson MA. Lack of synergy of erythromycin combined with penicillin or cefotaxime against Streptococcus pneumoniae in vitro. Antimicrob Agents Chemother 2003; 47: 1151-3.

136. Yoshioka D, Kajiwara C, Ishii Y, Umeki K, Hiramatsu K, Kadota J, et al. Efficacy of $\beta$-lactam-plus-macrolide combination therapy in a mouse model of lethal pneumococcal pneumonia. Antimicrob Agents Chemother 2016; 60: 614654.

137. Van Bambeke F, Tulkens PM. The role of solithromycin in the management of bacterial community-acquired pneumonia. Expert Rev Anti Infect Ther 2016; 14 : 311-24.

138. Farrell DJ, Mendes RE, Jones RN. Antimicrobial activity of solithromycin against serotyped macrolide-resistant Streptococcus pneumoniae isolates collected from U.S. medical centers in 2012. Antimicrob Agents Chemother 2015; 59: 2432-4.

139. Viasus D, Ramos O, Ramos L, Simonetti AF, Carratalà J. Solithromycin for the treatment of community-acquired bacterial pneumonia. Expert Rev Respir Med 2017; 11: 5-12.

140. Yamamoto K, Yamamoto S, Ogasawara N, Takano K, Shiraishi T, Sato T, et al. Clarithromycin prevents human respiratory syncytial virus-induced airway epithelial responses by modulating activation of interferon regulatory factor-3. Pharmacol Res 2016; 111: 804-14.

141. Harada T, Ishimatsu Y, Hara A, Morita T, Nakashima S, Kakugawa T, et al. Premedication with clarithromycin is effective against secondary bacterial pneumonia during influenza virus infection in a pulmonary emphysema mouse model. J Pharmacol Exp Ther 2016; 358: 457-63.

142. Sun K, Metzger DW. Inhibition of pulmonary antibacterial defense by interferon-gamma during recovery from influenza infection. Nat Med 2008; 14: 558-64.

143. Trinchieri G. Type I interferon: friend or foe? J Exp Med 2010; 207: 2053-63. 
144. Lorenzo M, Moretl, Sarria B, Cases E, Cortijo J, Méndez R, et al. Lung inflammatory pattern and antibiotic treatment in pneumonia. Respir Res 2015; 16: 15.

145. Statt S, Ruan JW, Hung LY, Chang CY, Huang CT, Lim JH, et al. Statinconferred enhanced cellular resistance against bacterial pore-forming toxins in airway epithelial cells. Am J Respir Cell Mol Biol 2015; 53: 689-702.

146. Rosch JW, Boyd AR, Hinojosa E, Pestina T, Hu Y, Persons DA, et al. Statins protect against fulminant pneumococcal infection and cytolysin toxicity in a mouse model of sickle cell disease. J Clin Invest 2010; 120: 627-35.

147. Feldman C, Anderson R. Community-acquired pneumonia. Pathogenesis of acute cardiac events and potential adjunctive therapies. Chest 2015; 148: 52332.

148. Viasus D, Garcia-Vidal C, Simonetti AF, Dorca J, Llopis F, Mestre M, et al. The effect of simvastatin on inflammatory cytokines in community-acquired pneumonia: a randomised, double-blind, placebo-controlled trial. BMJ Open 2015; 5: e006251.

149. Havers F, Bramley AM, Finelli L, Reed C, Self WH, Trabue C, et al. Statin use and hospital length of stay among adults hospitalized with community-acquired pneumonia. Clin Infect Dis 2016; 62: 1471-8.

150. Wootton DG, Diggle PJ, Court J, Eneje O, Keogan L, Macfarlane L, et al. Recovery from pneumonia requires efferocytosis which is impaired in smokers and those with low body mass index and enhanced by statins. Thorax 2016; 71: 1052-4. doi: 10.1136/thoraxjnl-2016-208505.

151. Patel J, Greenwood H, Lugg S, Howells P, Gao F, Sapey E, et al. Simvastatin improves neutrophil migration in elderly patients with septic pneumonia and reduces 6-month mortality and re-admissions: results of the SNOOPI Trial. Thorax 2016; 71; Suppl 3: A11. doi: 10.1136/thoraxjnl-2016-209333.22.

152. Grudzinska FS, Dancer R, Thickett D. Concurrent statin and macrolide use during pneumonia treatment improves survival to hospital discharge and beyond. Thorax 2016; 71; Suppl 3: A231. doi: 10.11.3/thoraxjnl-2016-209333.408.

153. Tintinger GR, Anderson R, Feldman C. Pharmacological approaches to regulate neutrophil activity. Semin Immunopathol 2013; 335: 395-409.

154. Barnes PJ. Glucocorticosteroids: current and future directions. $\mathrm{Br} \mathrm{J}$ Pharmacol 2011; 163: 29-43. 
155. Hua G, Ganti KP, Chambon P. Glucocorticoid-induced tethered transrepression requires SUMOylation of GR and formation of a SUMOSMRT/NCoR1-HDAC3 repressing complex. Proc Natl Acad Sci U S A 2016; 113: E635-43.

156. Wagner HN Jr, Bennett IL Jr, Lasagna L, Cluff LE, Rosenthal MB, Mirick GS. The effect of hydrocortisone upon the course of pneumococcal pneumonia treated with penicillin. Bull Johns Hopkins Hosp 1956; 98: 197-215.

157. du Cheyron D, Lesage A, Le Page O, Flais F, Leclercq R, Charbonneau P. Corticosteroids as adjunctive treatment in Austrian's syndrome (pneumococcal endocarditis, meningitis, and pneumonia): report of two cases and review of the literature. J Clin Pathol 2003; 56: 879-81.

158. Lavi E, Shoseyov D, Simanovsky N, Brooks R. Systemic steroid treatment for severe expanding pneumococcal pneumonia. Case Rep Pediatr 2015; 2015: 186302.

159. Damjanovic D, Lai R, Jeyanathan M, Hogaboam CM, Xing Z. Marked improvement of severe lung immunopathology by influenza-associated pneumococcal superinfection requires the control of both bacterial replication and host immune responses. Am J Pathol 2013; 183: 868-80.

160. Ghoneim HE, McCullers JA. Adjunctive corticosteroid therapy improves lung immunopathology and survival during severe secondary pneumococcal pneumonia in mice. $J$ Infect Dis 2014; 209: 1459-68.

161. Siemieniuk RA, Meade MO, Alonso-Coello P, Briel M, Evaniew N, Prasad M, et al. Corticosteroid therapy for patients hospitalized with community-acquired pneumonia: A systematic review and meta-analysis. Ann Intern Med 2015; 163: 519-28.

162. Tagami T, Matsui H, Horiguchi H, Fushimi K, Yasunaga H. Low-dose corticosteroid use and mortality in severe community-acquired pneumonia patients. Eur Respir J 2015; 45: 463-72.

163. Feldman $\mathrm{C}$, Anderson R. Corticosteroids in the adjunctive therapy of community-acquired pneumonia: an appraisal of recent meta-analyses of clinical trials. J Thorac Dis 2016; 8: E162-71.

164. Wirz SA, Blum CA, Schuetz P, Albrich WC, Noppen C, Mueller B, et al. Pathogen- and antibiotic-specific effects of prednisone in community-acquired pneumonia. Eur Respir J 2016; 48: 1150-9. 
165. Blum CA, Nigro N, Briel M, Schuetz P, Ullmer E, Suter-Widmer I, et al. Adjunct prednisone therapy for patients with community-acquired pneumonia: a multicentre, double-blind, randomised, placebo-controlled trial. Lancet 2015; 385: 1511-8.

166. Snijders D, Daniels JM, de Graaff CS, van der Werf TS, Boersma WG. Efficacy of corticosteroids in community-acquired pneumonia: a randomized double-blinded clinical trial. Am J Respir Crit Care Med 2010; 181: 975-82.

167. Zhang S, Wang J, Chen S, Yin J, Pan Z, Liu K, et al. Effects of suilysin on Streptococcus suis-induced platelet aggregation. Front Cell Infect Microbiol 2016; 6: 128.

168. Zhang S, Zheng Y, Chen S, Huang S, Liu K, Lv Q, et al. Suilysin-induced platelet-neutrophil complexes formation is triggered by pore formation-dependent calcium influx. Sci Rep 2016; 6: 36787.

169. De Stoppelaar SF, van 't Veer C, van der Poll T. The role of platelets in sepsis. Thromb Haemost 2014; 112: 666-77.

170. Claushuis TA, van Vught LA, Scicluna BP, Wiewel MA, Klein Klouwenberg PM, Hoogendijk AJ, et al. Thrombocytopenia is associated with a dysregulated host response in critically ill sepsis patients. Blood 2016; 127: 3062-72.

171. Cangemi R, Casciaro M, Rossi E, Calvieri C, Bucci T, Calabrese CM, et al. Platelet activation is associated with myocardial infarction in patients with pneumonia. J Am Coll Cardiol 2014; 64: 1917-25.

172. Cangemi R, Pignatelli P, Carnevale R, Bartimoccia S, Nocella C, Falcone M, et al. Low-grade endotoxemia, gut permeability and platelet activation in community-acquired pneumonia. J Infect 2016; 73: 107-14.

173. Winning J, Reichel J, Eisenhut Y, Hamacher J, Kohl M, Deigner HP, et al. Anti-platelet drugs and outcome in severe infection: clinical impact and underlying mechanisms. Platelets 2009; 20: 50-7.

174. Erlich JM, Talmor DS, Cartin-Ceba R, Gajic O, Kor DJ. Prehospitalization antiplatelet therapy is associated with a reduced incidence of acute lung injury: a population-based cohort study. Chest 2011; 139: 289-95.

175. O'Neal HR Jr., Koyama T, Koehler EA, Siew E, Curtis BR, Fremont RD, et al. Prehospital statin and aspirin use and the prevalence of severe sepsis and acute lung injury/acute respiratory distress syndrome. Crit Care Med 2011; 39: 134350 . 
176. Harr JN, Moore EE, Johnson J, Chin TL, Wohlauer MV, Maier R, et al. Antiplatelet therapy is associated with decreased transfusion-associated risk of lung dysfunction, multiple organ failure, and mortality in trauma patients. Crit Care Med 2013; 41: 399-404.

177. Falcone M, Russo A, Cangemi R, Farcomeni A, Calvieri C, Barillà F, et al. Lower mortality rate in elderly patients with community-onset pneumonia on treatment with aspirin. J Am Heart Assoc 2015; 4: e001595.

178. Panka BA, de Grooth HJ, Spoelstra-de Man A, Looney MR, Tuinman PR. Prevention or treatment of ARDS with aspirin: a review of preclinical models and meta-analysis of clinical studies. Shock 2016; 47: 13-21. doi:

10.1097/SHK.0000000000000745.

179. Kor DJ, Erlich J, Gong MN, Malinchoc M, Carter RE, Gajic O, et al. Association of prehospitalization aspirin therapy and acute lung injury: results of a multicenter international observational study of at-risk patients. Crit Care Med 2011; 39: 2393-400.

180. Kor DJ, Carter RE, Park PK, Festic E, Banner-Goodspeed VM, Hinds R, et al. Effect of aspirin on development of ARDS in at-risk patients presenting to the emergency department: the LIPS-A randomized clinical trial. JAMA 2016; 315: 2406-14.

181. Voiriot G, Dury S, Parrot A, Mayaud C, Fartoukh M. Nonsteroidal antiinflammatory drugs may affect the presentation and course of communityacquired pneumonia. Chest 2011; 139: 387-94.

182. Gibelin A, de Prost N, Brun-Buisson C. Lung abscess complicating pneumococcal pneumonia: a causal role of non-steroidal anti-inflammatory drugs? BMJ Case Rep 2013; 200544.

183. Messika J, Sztrymf B, Bertrand F, Billard-Pomares T, Barnaud G, Branger C, et al. Risks of nonsteroidal anti-inflammatory drugs in undiagnosed intensive care unit pneumococcal pneumonia: younger and more severely affected patients. $J$ Crit Care 2014; 29: 733-8.

184. Esposito AL. Aspirin impairs antibacterial mechanisms in experimental pneumococcal pneumonia. Am Rev Respir Dis 1984; 130: 857-62.

185. Stables MJ, Newson J, Ayoub SS, Brown J, Hyams CJ, Gilroy DW. Priming innate immune responses to infection by cyclooxygenase inhibition kills antibioticsusceptible and -resistant bacteria. Blood 2010; 116: 2950-9. 
186. Lee CH, Su LH, Liu JW, Chang CC, Chen RF, Yang KD. Aspirin enhances opsonophagocytosis and is associated to a lower risk for Klebsiella pneumoniae invasive syndrome. BMC Infect Dis 2014; 14: 47.

187. Shigematsu M, Koga $T$, Ishimori A, Saeki K, Ishii $Y$, Taketomi $Y$, et al. Leukotriene $B_{4}$ receptor type 2 protects against pneumolysin-dependent acute lung injury. Sci Rep 2016; 6: 34560.

188. Pan H, Boucher M, Kaunelis D. PAR-1 antagonists: an emerging antiplatelet drug class. In: CADTH Issues in Emerging Health Technologies. Canadian Agency for Drugs and Technologies in Health, Ottawa. 2016; 148. PMID 27809429.

189. José RJ, Williams AE, Mercer PF, Sulikowski MG, Brown JS, Chambers RC. Regulation of neutrophilic inflammation by proteinase-activated receptor 1 during bacterial pulmonary infection. J Immunol 12015; 194: 6024-34. 